Review

\title{
Surface Modifications of Nanofillers for Carbon Dioxide Separation Nanocomposite Membrane
}

\author{
Pei Sean Goh *, Kar Chun Wong, Lukka Thuyavan Yogarathinam, Ahmad Fauzi Ismail *, \\ Mohd Sohaimi Abdullah and Be Cheer Ng
}

\author{
Advanced Membrane Technology Research Centre, School of Chemical and Energy Engineering, \\ Universiti Teknologi Malaysia, Johor Bahru 81310, Malaysia; karchun88@outlook.com (K.C.W.); \\ lukkathuyavan-pd@utm.my (L.T.Y.); sohaimi@petroleum.utm.my (M.S.A.); \\ ngbecheer@petroleum.utm.my (B.C.N.) \\ * Correspondence: peisean@petroleum.utm.my (P.S.G.); afauzi@utm.my (A.F.I.)
}

Received: 31 May 2020; Accepted: 28 June 2020; Published: 2 July 2020

\begin{abstract}
CO}_{2}$ separation is an important process for a wide spectrum of industries including petrochemical, refinery and coal-fired power plant industries. The membrane-based process is a promising operation for $\mathrm{CO}_{2}$ separation owing to its fundamental engineering and economic benefits over the conventionally used separation processes. Asymmetric polymer-inorganic nanocomposite membranes are endowed with interesting properties for gas separation processes. The presence of nanosized inorganic nanofiller has offered unprecedented opportunities to address the issues of conventionally used polymeric membranes. Surface modification of nanofillers has become an important strategy to address the shortcomings of nanocomposite membranes in terms of nanofiller agglomeration and poor dispersion and polymer-nanofiller incompatibility. In the context of $\mathrm{CO}_{2}$ gas separation, surface modification of nanofiller is also accomplished to render additional $\mathrm{CO}_{2}$ sorption capacity and facilitated transport properties. This article focuses on the current strategies employed for the surface modification of nanofillers used in the development of $\mathrm{CO}_{2}$ separation nanocomposite membranes. A review based on the recent progresses made in physical and chemical modifications of nanofiller using various techniques and modifying agents is presented. The effectiveness of each strategy and the correlation between the surface modified nanofiller and the $\mathrm{CO}_{2}$ separation performance of the resultant nanocomposite membranes are thoroughly discussed.
\end{abstract}

Keywords: $\mathrm{CO}_{2}$ separation; nanocomposite membranes; surface modifications; nanofiller

\section{Introduction}

Gas separation and purification is an indispensable process that finds important place in many conventional and emerging industries. $\mathrm{CO}_{2}$ separation from different gas mixture is among the most important process [1]. Selective removal of $\mathrm{CO}_{2}$ is a crucial process in natural gas processing and biogas purification. In petrochemical industries, huge efforts have been made in developing high performance gas separation process for $\mathrm{CO}_{2} / \mathrm{CH}_{4}$ separation [2]. Removal of $\mathrm{CO}_{2}$ from natural gas is essential to improve the calorific value of the gas. The growing natural gas demand has led to the re-exploration of significant contaminated or sub-quality natural gas reserves that were previously considered as not economically viable. The presence of more than $10 \%$ of $\mathrm{CO}_{2}$ and $\mathrm{H}_{2} \mathrm{~S}$ in these sour reserves brings great challenge to the gas processing during the removal of this high fraction of acidic gases [3]. In terms of pipeline transportation, $\mathrm{CO}_{2}$ must be removed and reduced to fulfill the pipeline specification and distribution quality standard during the transportation of the natural gas. The maximum level of $\mathrm{CO}_{2}$ is typically below $3 \%$ to avoid the corrosion of pipeline and equipment by the acidic gas $[3,4]$. Biogas produced naturally from the decomposition of organic matters is an alternative energy source 
of fossil fuel. To harness its advantage, biogas upgrading is needed to increase the content of $\mathrm{CH}_{4}$ from $50-75 \%$, depending on the source of biogas, to $>95 \%$ [5]. The removal of impurities, particularly $\mathrm{CO}_{2}$ is necessary to increase the biogas quality for further usage [6,7].

On the other hand, global warming has been recognized as one of the major challenges for the 21st century. Power plants and industries such as steel and petrochemical industries have been known as the major contributors with significant share in global greenhouse emission $[8,9]$. Sustainable solutions have been called to halt climate change and solve this urgent problem. As the primary anthropogenic greenhouse gas, different strategies have been deployed to reduce the direct emission of $\mathrm{CO}_{2}$ into the atmosphere [10]. Along this development, carbon capture and storage has become the most indicated technology from the energy utilization perspective [11-14]. The selection of carbon capture technology is determined by many factors including the types of fuel used as well as the $\mathrm{CO}_{2}$ generating and release sources. Traditionally, $\mathrm{CO}_{2}$ separation has been performed through cryogenic distillation [15], adsorption [16,17] and absorption [18]. Despite the maturity of these processes owing to their long history in industries, conventional $\mathrm{CO}_{2}$ separation techniques suffer from several limitations. For example, the utilization of amine-based absorption is challenged by amine degradation, solvent and generation of volatile by-products [19]. The operation of absorption process to treat high fraction of highly concentrated acidic gases is not economically favorable as the operating cost increases proportionally with the concentration of acid in the feed stream gas. An efficient $\mathrm{CO}_{2}$ separation process is desired, not only to achieve high purity product, but also to offer significant energy and cost savings. The stringent requirement for higher purity products is an important driver that pushes the implementation of more efficient separation process in the these industries [20]. The opportunities of membrane-based gas separation in various applications expand exponentially over the last few decades owing to their attractive techno-economical features in relative to the conventional processes [21,22]. Membrane technology benefits from advantages including small footprint, high process flexibility, low energy consumption and low capital cost, hence offer greater potential for long term and sustainable implementation. As an economically appealing option that is also environmentally attractive, membrane system has been replaced or integrated and retrofitted with the existing system to complement the conventional separation techniques [23].

The membrane is the heart of the membranes-based $\mathrm{CO}_{2}$ separation process. A gas separation membrane should offer high permeability and selectivity as well as mechanical, chemical and thermal stability throughout the operation [24]. Economic competitiveness is another key requirement feature of membrane for attractive commercial application. Polymeric and inorganic membranes are two major classes of gas separation membrane. The intrinsic properties of the membrane materials decisively affect the economic factors of the membrane-based gas separation process as they are associated to the separation performances of the membranes, the energy consumption and the membrane area required for the separation [25]. As such, constant improvements have been made in the development of these membranes at both bench and commercial scales [26]. Endowed with characteristics such as simplicity of manufacturing and lower cost, polymeric membranes are advantageous over the inorganic counterpart, hence progressing in a faster pace in both research development and industrial applications [27]. Polymeric gas separation membranes have been successfully introduced in enhanced oil recovery and natural gas purification since the early 1980s and account for more than $\$ 1$ billion/year commercial gas separation market [28]. The major issue with polymeric membranes is the ubiquitous permeability-selectivity trade-off, in which a highly permeable polymer is usually less selective and vice versa [29]. Porous and nonporous inorganic materials such as metal oxides and zeolite provide an alternative to produce membranes that are highly selective and permeable as well as robust to withstand harsh conditions [30]. However, inorganic membranes are still far from being competitive in the marketplace due their bottlenecks which are related to the cost, brittleness and difficulty in processing and modular design for practical large-scale usage.

Due to the performance and processing trade-off issue pertaining to commercially used polymeric and inorganic membranes, material scientists are venturing for innovations that can address these 
constraints [31]. Breaking the permeability-selectivity trade-off and striking a balance between performance and cost effectiveness are the prioritized tasks in the development of gas separation membranes. These requirements have urged the transformations from conventional polymer and inorganic membranes to a new generation of gas separation membrane that combines the distinct attractive properties of polymer and inorganic material in a single entity. The development of new generation nanocomposite membranes is motivated by the synergistic effects attained from the excellent intrinsic separation properties of inorganic materials and the high processability and mechanical stability of polymers. Nanocomposite membranes, more commonly known as mixed matrix membranes (MMM), are prepared by dispersing inorganic nanofillers in a continuous polymer matrix. Since the first attempt of incorporating zeolite 5A into polydimethyl siloxane back in the 1970s, the development of gas separation nanocomposite membranes has been at the forefront and demonstrates a paradigm shift in the state-of-the-art gas separation membranes. Currently, a wide range of nanomaterials with different dimensions, geometries and functionalities have been investigated as potential nanofiller to heighten the performances of polymeric membranes for $\mathrm{CO}_{2}$ gas separation [32-39].

The potentials in advancing polymeric membranes using nanomaterials are tremendous. To date, hundreds of nanomaterials have been applied as nanofillers of nanocomposite membranes. The characteristics and performance of the resultant nanocomposite gas separation membranes are governed by factors such as the features of nanomaterials at atomic and macroscopic level, nanofiller loading, orientation of anisotropic nanomaterial and the interfacial properties such as compatibility and interaction between the nanofillers and polymer matrix [40]. One of the important criteria in the fabrication of nanocomposite membrane for gas separation is to ensure the compatibility between the two phases so that the integrity of the membrane is not compromised. Surface modification of nanomaterials prior to introduction into the polymer matrix has become a common practice in the preparation of nanocomposite membranes to mitigate this issue. Surface modifications, which can be accomplished through physical or chemical approaches, introduce functional groups that are crucial to reduce the agglomeration of nanofillers as a result of high specific surface area and volume effect of the nanomaterials. The surface modification facilitates the dispersibility of the nanofillers during membrane preparation, hence improving the interfacial interaction between the nanofiller and polymer matrix in the resultant nanocomposite membrane [41-43]. In the context of $\mathrm{CO}_{2}$ gas separation, the modification of nanofiller with reactive group has also been pursued to tailor their specific sorption capacities and selectivity towards $\mathrm{CO}_{2}$ molecules [44-46].

A body of literature indicates the feasibility of surface modification in addressing the current issues related to the limitations of gas separation nanocomposite membranes [47-51]. The reviews on this topic are crucial to assess the achievement made to date and outline the possible ways for further improvement. Ma et al. reviewed the strategies to engineer the polymer-nanofiller interface of metal organic framework (MOF) incorporated MMM for gas separation [52]. Amooghin et al. presented a comprehensive review on the development of $\mathrm{MMM}$ for $\mathrm{CO}_{2}$ separation and highlighted the importance of surface functionalization for both nanofiller and polymers to enhance gas separation performance [53]. In view of the importance of $\mathrm{CO}_{2}$ separation and potentials of nanocomposite membrane for commercial application, this review aims to provide insights into the current nanofiller modification methods for nanocomposite membrane preparation. Firstly, an overview of the polymers and nanomaterials used in the development of nanocomposite membrane for $\mathrm{CO}_{2}$ separation is presented. The intrinsic properties and unique features of the emerging polymeric materials and nanomaterials are highlighted. In the following section, the purposes and motivations of performing nanofiller modification are justified. Next, the approaches used for nanofiller modifications are comprehensively reviewed. The $\mathrm{CO}_{2}$ gas separation performance of the resultant nanocomposite is evaluated and summarized. Although the post-modification of nanocomposite membrane for $\mathrm{CO}_{2}$ separation is also common, this review focuses on the surface modification of nanomaterials through various physical and chemical strategies prior to their direct incorporation into the polymer matrix. 
Finally, the challenges and perspective are discussed to provide guidelines for potential future research in this field.

\section{Polymers and Nanomaterials in $\mathrm{CO}_{2}$ Separation Nanocomposite Membranes}

Besides facing the permeability-selectivity trade-off, polymeric materials are known to suffer from poor chemical and thermal resistance [54-56]. Polymeric membranes are susceptible to concentrated organic and corrosive solvents which can be normally found in industrial chemical constituents. The dissolution and swelling of the polymeric structure impair the selectivity of the membrane and shorten the membrane life expectancy. High temperature operation disrupts the integrity of the polymeric membrane by inducing structural and physical changes to the polymeric chains. The membrane loses its ability to discriminate gas molecules due to the increased segmental flexibility of the backbone structures. Physical aging and plasticization are two mobility-related issues that have detrimental effects on the separation performance of the polymeric membranes [57]. Long-term physical aging is associated to permanent densification of polymer chains due to the rearrangement of glassy polymeric chains to attain a stable configuration. The gradually shrunk microvoids and interstitial space between the polymer chains results in the decrease in free volume and eventually the loss of membrane permeability. Plasticization has significant implication in $\mathrm{CO}_{2}$ separation as it is related to the swelling of the polymer due to high sorption of a condensable gas such as $\mathrm{CO}_{2}[24,58]$. The incorporation of nanomaterials into the polymeric matrix offer an unprecedented opportunity to curb the intrinsic issues of polymeric membranes and to satisfy the criteria of a membrane that is readily deployed for industrial application [59-63].

Over the past decades, numerous polymer materials with promising transport properties have been engineered and studied at bench scale. The synthetic composition of polymeric materials allows high flexibility in tailoring the properties of membranes during the fabrication. The organic chemistry can be conveniently tuned to attain desired polymer structure through pre- and post-fabrication modification [64-66]. Polymer selection is a key subject in the preparation of gas separation membranes as it determines the intrinsic separation properties of the membranes and limits the processing methods and chemicals used in the fabrication process. The physico-chemical properties and separation efficiency of the polymer materials in terms of thermal stability, aging behavior, solubility and diffusivity should be carefully assessed. Although glassy polymers such as polyimide, polysulfone (PSf) and cellulose acetate have been commonly used for the preparation of $\mathrm{CO}_{2}$ separation membranes, it has been generally observed that nanocomposite membranes based on highly permeable polymers such as 6FDA-(6FDA = 4, $4^{\prime}$-(hexafluoroisopropylidene) diphthalic anhydride) containing polyimides exhibit separation performance above the revisited Robeson upper bound while less permeable polymers such as PSf demonstrate separation behaviors that are below the state of the art [67].

Polyimide (PI) is an important class of polymeric material for gas separation membrane, particularly 6FDA-based polyimide materials that exhibit high rigidity and tunable transport properties [68]. Compared to classical PI, 6FDA-based PI contains fluorine groups in the forms of hexafluoroisopropylidene, perfluoroalkyl and pendent trifluoromethyl linkages which can effectively alter the molecular movement and increase the free volume. A new type of polymer based on Tröger's Base units has been developed, where rigid and in-built amine structure are constructed to enhance the stiffness of the polymer chain backbone thus improve the gas separation. Tröger's Base-based PI membranes demonstrated strong interaction between $\mathrm{CO}_{2}$ and nitrogen atoms of tertiary amine of Tröger's Base, hence significantly improve $\mathrm{CO}_{2}$ separation [69]. Polymers of intrinsic microporosity (PIM), which consist of bulky polymer backbones with no rotational freedom, are amorphous glassy polymers with unique structural properties that are different from other glassy polymers [70]. The "microporosity" structure of PIMs allows high free volume and surface area for sorption, hence the gas separation performance of PIM falls beyond the Robeson upper bound [71,72]. However, only a handful of PIM structures have been reported to date due to the limited choice of monomers [73]. Thermally rearranged polymer are polymers that are thermally treated to render more 
free volume. Thermal rearrangement involves the decarboxylation of a soluble PI precursor at elevated temperatures in order to form microcavities with narrow size distribution in the polymer structure. The thermally rearranged polymers exhibit higher gas permeability and higher tolerance towards plasticization compared to their corresponding precursors, with marginal loss of selectivity [74].

Rubbery polymers have also received great attention in gas separation membrane development. In contrast to glassy polymers, rubbery polymers usually have high gas permeability but a relatively low selectivity. With the ethylene oxide (EO) groups in its back bone structure to show high affinity towards $\mathrm{CO}_{2}$, poly(ethylene oxide) (PEO) is known as a good candidate for $\mathrm{CO}_{2}$ separation $[75,76]$. The EO content also provides more free volume by impeding the packing of polymer chains. One of the most widely used PEO containing copolymer is poly(ether-block-amide) (PEBA), a thermoplastic polymer with aliphatic polyamide hard segment and PEO soft segment. While the PEO phase provides continuous pathway for gas diffusion, the polyamide block provides mechanical stability and inhibits crystallization of PEO. Polyurethane (PU) is a rubbery polymer made from the polyaddition reactions of diol or polyol, diisocyanate or polyisocyanate and a chain extender. PU is also known as a good option for $\mathrm{CO}_{2}$ gas separation membrane due to high solubility of polar and acidic gases. Facilitated transport membranes are another class of membrane which have been commonly investigated due to their ability to simultaneously enhance $\mathrm{CO}_{2}$ permeability and gas selectivity [77]. Poly(vinylamine) (PVAm) is a cationic linear polymer with abundant primary amine groups which facilitate transport mechanisms. With this interesting feature, PVAm has been widely used as the selective layer of composite membrane [78-80]. PVAm is commonly crosslinked with a mechanically robust polymer such as polyvinyl alcohol (PVA) to resolve the issue related to structural instability upon exposure to high humidity [81].

Selecting a nanofiller that matches the physico-chemical properties of polymers and fits in the features of gas pair to be separated are the two main criteria to realize the desired separation outcomes. Polymer-sieve theory states that, if the gas permeability of the selected nanofiller is far higher than that of the polymer host, the limited molecular sieving property of the nanofiller would restrict the gas separation performance of the nanocomposite, especially when small amount of nanofiller is used [82]. As such, the sieving capability, adsorption capacity and gas permeability of nanofiller must be carefully assessed to match the transport properties of the polymer host. In the early stage, the development of nanocomposite membrane was mainly focused on the utilization of nanofillers with molecular sieve properties such as zeolite [83] and carbon molecular sieve [84]. The size exclusion capability of these inorganic nanofillers is harnessed to enhance the membrane selectivity. With the discovery of more advanced nanomaterials with multiple functionalities or attractive geometrical structures, more studies are now directed to the application of these exciting nanomaterials.

Zeolite is the most classical nanofiller applied in gas separation nanocomposite membrane. Zeolite are endowed with rigid porous structures, regular intercystalline cavities and channels in molecular dimension, hence exhibiting precise molecular sieving ability [85]. The adsorption and diffusion of gas molecules across zeolite are determined by the size of the channel cavities, therefore it is crucial to select a zeolitic molecular sieve with the precise dimensions to discriminate the identified gas penetrants. One of the most commonly studied classes of zeolite is zeolite Linde Type A (LTA), which can be further classified as Zeolite 3A, 4A or 5A [86]. Zeolite LTA has demonstrated high $\mathrm{CO}_{2}$ uptake capability as well as chemical and thermal stability, hence can be suitably used as nanofiller of gas separation nanocomposite membranes. Zeolites with eight-membered oxygen rings such as deca-dodecasil 3 rhombohedral (DD3R), silicoaluminophosphate (SAPO)-34 [87,88], SSZ-13 and T-type [89] have been investigated for their potential in gas separation. Although zeolite is one of the most explored porous nanofillers for nanocomposite gas separation membranes, unexpectedly low separation performance, especially gas selectivity, has been observed in most studies. The poor compatibility between inorganic zeolites and organic polymers is the primary reason leading to interfacial defects and formation sieve-in-a-cage structure [90]. 
MOF is a relatively new class of crystalline porous materials with three-dimensional (3D) network of metal-containing units or secondary building units held in place by multidentate organic linkers. MOFs have been explored for separation owing to their well-defined pore sizes and channels which render separation properties superior to zeolites and carbon molecular sieve [91]. In addition, some MOFs such as zirconium-based UiO-66 also exhibit strong affinity towards $\mathrm{CO}_{2}$ molecules due to the presence of -OH groups attached to the zirconium cluster [92]. Zeolitic imidazolate frameworks (ZIF) are a sub-class of MOF. ZIF-8 has been extensively studied as the large internal cavities allow fast gas diffusion while the small pore apertures separate gas pairs such as $\mathrm{CO}_{2} / \mathrm{CH}_{4}$ and olefin/paraffin [93]. Recently, more ZIF members such as ZIF-67 [94], ZIF-78 [95], ZIF-90 [96] and ZIF-300 [97] been explored as the substitute of ZIF-8 for gas separation applications. The attractive feature of MOF as a nanofiller is rendered by the organic linkers which act as bridging medium to facilitate polymer-nanofiller compatibility during the fabrication of nanocomposite membranes. However, not all functional groups of the organic linkers that are compatible with the polymers can be used for the MOF synthesis as most of these linkers are unstable under the chemical and high temperature solvothermal synthesis environment [98]. Therefore, post-synthetic chemical functionalization is a more convenient option to introduce new functional groups and refine the MOF properties [99]. Amine-functionalized MOFs are conferred with significantly improved $\mathrm{CO}_{2}$ adsorption capacity and increased $\mathrm{CO}_{2}$ separation factor $[100,101]$. For example, $\mathrm{NH}_{2}$-MIL-53 with different geometrical structure has exhibited outstanding selectivity in $\mathrm{CO}_{2} / \mathrm{N}_{2}$ separation [102]. UiO-66- $\mathrm{NH}_{2}$ has enhanced $\mathrm{CO}_{2}$ adsorption capacity and selectivity based on the base-acid and dipole-quadrupole interactions of the functionalized basic nitrogen sites with the polarizable $\mathrm{CO}_{2}$ molecules [103].

Carbon-based nanomaterials of different structure, geometries and dimensions have drawn tremendous attentions in the development of nanocomposite membranes for various applications. Carbon nanotubes (CNT), which can be produced in single- or multiwalled forms, are a $\mathrm{sp}^{2}$ carbon bonded tubular nanomaterial made from rolled-up graphene sheets. The ultrafast molecular transport through CNT for gas adsorption and separation has been computationally $[104,105]$ and experimentally $[41,106-108]$ evidenced. Graphene-family nanomaterials are promising nanofiller for gas separation membrane. They exhibit large surface-to-volume ratio, high gas adsorption capability and promising mechanical strength. Graphene-family nanomaterials for gas separation applications have been synthesized in the forms of nanoporous graphene, graphene laminate and graphene-based composites. Graphene oxide (GO) is known as functionalized graphene sheets characterized by abundant oxygen containing functional groups on its surface. The functional groups allow good interaction with the polymer matrix during nanocomposite processing. The interlayer spacing of $\mathrm{GO}$ can be catered to provide a selective transport pathway and permeation of specific gas molecules $[109,110]$.

Metal oxides nanoparticles such as $\mathrm{TiO}_{2}, \mathrm{Fe}_{3} \mathrm{O}_{4}$ and $\mathrm{CuO}$ are also important nanofiller materials due to their promising textural properties and well-established synthesis techniques. $\mathrm{CO}_{2}$ can bound to a metal center through several coordinations such as metal-carbon coordination, metal-oxygen coordination and chelating bent [111]. The interaction between the surface $\mathrm{OH}$ groups of metal oxide with polar $\mathrm{CO}_{2}$ molecules increases the adsorption capability of acidic $\mathrm{CO}_{2}$ [112]. The interaction of $\mathrm{CO}_{2}$ with defect free $\mathrm{ZnO}$ surface has been investigated experimentally and theoretically [113]. The oxide layer increased the solubility of $\mathrm{CO}_{2}$, hence improving the gas permeance [114]. Ahmadizadegan et al. demonstrated that $\mathrm{ZnO}$ incorporated into polymer matrix could enhance the permeability of $\mathrm{N}_{2}, \mathrm{O}_{2}$, $\mathrm{CH}_{4}$ and $\mathrm{CO}_{2}$ due to the increased diffusivity and solubility [115]. Layered double hydroxides (LDHs) are two-dimensional nanomaterials with uniform interlayer galleries. $\mathrm{LDH}$ is made up of regularly arranged brucite-like cationic layers and charge-balancing anions in the hydrated interlayer. The $\mathrm{CO}_{2}$ adsorption of LDH has been widely studied [116]. The interlayer spacing of LDH can be tailored to permit rapid transport of smaller molecules such as $\mathrm{CO}_{2}$ and hinder the passage of large molecules.

$\mathrm{CO}_{2}$ separation nanocomposite membranes can be fabricated into two structures, namely MMM and multilayer thin film nanocomposite. For MMM, nanofillers are introduced into the polymer dope and followed by phase inversion technique to form the nanocomposite membranes. The preparation 
of multilayer thin film nanocomposite involves the formation of selective layer onto a substrate which acts as a mechanical support $[117,118]$. In the typical top-down approach, the selective layer is formed through solvent evaporation technique, where the nanofillers are suspended in the selective layer polymer dope. Alternatively, more advanced bottom-up approaches such as polymer grafting assembly and interfacial polymerization have also been established to gain more precise control on the thin film formation through the assembly of small building blocks [117]. In these approaches, the nanofillers are suspended in the monomer solutions prior to the polymerization to form the selective layer.

\section{Surface Modifications of Nanomaterials-The Motivations}

The interaction and interfacial properties at the polymer-nanofiller boundary are complex. Both gas permeation experimental findings and computational modeling are needed to provide better understanding in this subject. The incorporation of nanofiller induces several significant changes to the polymer host matrix, which include: (i) formation of tortuous paths; (ii) rigidification of polymer chains surrounding the nanofillers; (iii) formation of interfacial voids, in the form of polymer-nanofiller interstitial cavities and nonselective voids with discrete interfacial properties; and (iv) partial or full blockage of the pores or cavities of nanofillers by the polymer chains. Non-ideal defective structures are inevitably formed due to the incommensurable physico-chemical properties of the polymer and inorganic phases. Besides the polymer-nanofiller incompatibility, the formation of non-ideal morphologies can also be attributed to stresses created from solvent evaporation during the precipitation of membrane, disruption of polymer packing and repulsive force between the two phases [119].

To retain the integrity of the membrane and maximize the nanoscale effects of nanofiller in nanocomposite membranes, the polymer-filler compatibility as well as the uniformity of nanofiller within the continuous polymer matrix must be carefully monitored. Unfortunately, pristine nanofiller normally suffer from concerning dispersion and compatibility issue due to the chemical composition and phases that are distinctively different from that of polymeric material. Particularly, nanocomposite membrane consisting of glassy polymer exhibits poor polymer-nanofiller compatibility and interfacial interaction due to the rigidity of the glassy polymer chains. During the solidification of membrane, the disruption of the polymer chains packing in the vicinity of the nanofiller resulted in void formation [120]. It has been commonly observed that most experimental $\mathrm{CO}_{2}$ separation results of nanocomposite membranes were far below that of theoretical maximum, mainly due to nanofiller agglomeration and poor interfacial interaction [121]. Regardless of the size-exclusion properties and distribution of the nanofiller within the polymer matrix, the presence of negligible interfacial voids allows the non-selective bypassing of most gas species, hence severely compromising the membrane selectivity. Macroscopic membrane defects are also created due to the introduction of agglomerated nanofiller. During the formation of multilayer thin film nanocomposite, the agglomerated nanofillers protrude from the polymer layer and disrupt the continuous growth of the selective layer. As the agglomerated nanofiller can easily detach from the selective layer, non-selective voids are formed through the film surface [122]. With these detrimental effects, the gas separation of the nanocomposite could only be marginal improved and the other issues such as membrane aging could not be effectively suppressed [123].

Despite the potential of inorganic nanofillers in enhancing the physico-chemical characteristic and gas separation performance of conventional polymeric membranes, only handful of these nanofillers could be directly used in their pristine or as-synthesized form for the development of nanocomposite membranes. For instance, the surface of GO nanosheet is rich with polarized oxygen containing functional groups. This surface chemistry allows the formation of hydrogen bonding between the nanosheet with polymers such as Pebax, in which the $-\mathrm{N}-\mathrm{H}-, \mathrm{H}-\mathrm{N}-\mathrm{C}=\mathrm{O}$ and $\mathrm{O}-\mathrm{C}=\mathrm{O}$ functional groups are also abundant at the polymer backbone structure. The hydrogen bonding, as illustrated in Figure 1 , not only facilitates the dispersion of GO nanosheet, but also controls the assembly and stacking behavior of the nanofiller to form molecular-sieving interlayer spacing that act as diffusion pathways [124]. 
On the other hand, MOF nanofillers are also inherently more adaptable to glassy polymers compared to zeolites and other inorganic crystalline structures, owing to the presence of multidentate organic groups. Despite the intrinsic advantage of these nanofillers to achieve adequate interfacial interaction with their well-matched polymer host matrix, it has been generally observed that the dispersion state of pristine nanofiller could only be maintained at low nanofiller loading of below $1 \mathrm{wt} \%$. When pristine non-dried ZIF-8 was embedded into Matrimid, the good compatibility between the nanofiller and polymer matrix diminished at loading $>20 \mathrm{wt} \%$ where the formation of non-selective voids resulted in enhanced $\mathrm{CO}_{2}$ permeability that accompanied severely decreased selectivity [125]. It should be pointed out that, although good dispersion could be easily achieved at low loading, the transport behavior of the resultant nanocomposite membranes may not be improved in a significant way. The incorporation of sufficiently high loading of nanofiller to achieve the percolation threshold is important to maximize the effects of the nanofiller.

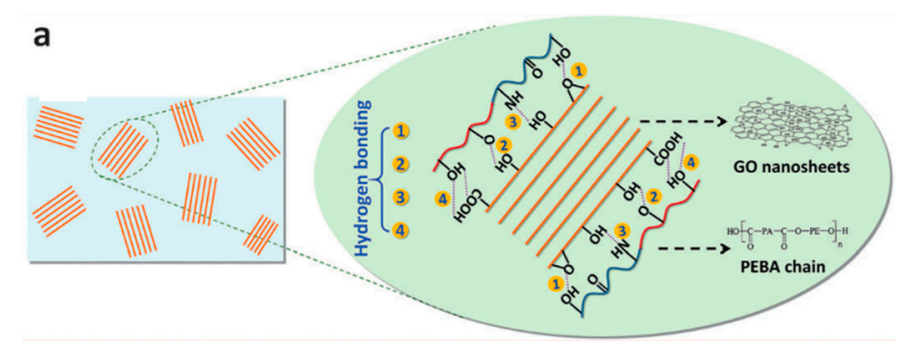

Figure 1. Schematic illustration of establishment of hydrogen bonding between GO nanosheets and Pebax polymer backbone structure [121].

Many attempts have been made to improve the interaction between polymer and nanofiller. While proper selection of compatible polymer host and nanofillers remains the most straightforward practice, other approaches such as priming of nanofiller [126], controlling the dope preparation and membrane fabrication parameters [127] and in-situ growth of nanofiller [128] have also been investigated. During the preparation of nanocomposite membrane for gas separation, the dispersion and distribution of the nanofiller in the dope solution can be improved through mechanical milling [108] and agitation such as high speed mixer and ultrasonication [129]. Thompson et al. observed the change in the microstructure of gas permeation behavior of Matrimid ${ }^{\circledR}$-based nanocomposite incorporated with ZIF-8 when subjected to different sonication condition [129]. With sufficiently high direct ultrasonication intensity up to $156 \mathrm{~W} / \mathrm{cm}^{2}$, the nanofiller aggregates were fully broken apart due to the Ostwald ripening of ZIF-8 in the presence of THF solvent. However, the crystallinity and microporosity of ZIF-8 were also disrupted during the process, thus adversely affecting the nanoparticle morphology and size-exclusion properties.

In-situ growth of nanofiller within polymer has become a more popular approach in recent years to mitigate the issues related to agglomeration and gravitational settling of the nanofiller in the dope solution $[129,130]$. One way to in-situ grow nanofillers is during the precipitation of the membrane where in-situ chemical reduction is performed in the coagulation bath to transform the precursor to the nanofiller [131]. As nanofiller agglomeration and settling is no longer an issue during the preparation, high loading of nanofiller can be incorporated into the polymer matrix. However, despite the advantages, the in-situ growth technique is limited to nanofillers that can be synthesized through room temperature sol-gel or in-situ polymerization. Therefore, in-situ growth method is not technically viable for the preparation of nanocomposite membranes incorporated with carbon-based nanomaterials and some crystalline nanofillers which involve more complex and high temperature synthesis routes. Priming technique is introduced to enhance homogeneity of nanofiller in the polymer suspension [84]. Priming can help to minimize the aggregation and promote the compatibility of the two phases through the coating of a thin layer of polymer onto the nanofiller particles. Nevertheless, 
this technique is less effective for nanofillers that are lacking of surface polarity and functionality, especially when they are added in high loading to the priming slurry.

Facilitated transport is an important mechanism for $\mathrm{CO}_{2}$ transport across the membrane. In a $\mathrm{CO}_{2}$ facilitated transport membrane, $\mathrm{CO}_{2}$ molecules are transported by means of their reversible reaction with the fixed or mobile carriers, while the nonreactive species such as $\mathrm{N}_{2}$ and $\mathrm{CH}_{4}$ could only permeate through solution diffusion mechanisms. Therefore, improving the adsorption capability of these nanofillers towards $\mathrm{CO}_{2}$ is another attractive approach to enhance the $\mathrm{CO}_{2}$ gas separation performance of the membrane [132]. The Lewis acid-Lewis base interactions between $\mathrm{CO}_{2}$ and amineor N-containing organic molecules such as pyridine, imidazole and tetrazole has been well established. Through these interactions, the solubility of $\mathrm{CO}_{2}$ is increased compared to other non-reactive gas species. The amine containing groups chemically interact with $\mathrm{CO}_{2}$ to form carbamates and bicarbonates in anhydrous and hydrous conditions, respectively, as shown in Equations (1) and (2) [133]:

$$
\begin{gathered}
\mathrm{R}-\mathrm{NH}_{2}+\mathrm{CO}_{2} \rightarrow \mathrm{R}-\mathrm{NHCO}_{2}^{-}+\mathrm{H}^{+} \\
\mathrm{R}-\mathrm{NH}_{2}+\mathrm{CO}_{2}+\mathrm{H}_{2} \mathrm{O} \rightarrow \mathrm{R}-\mathrm{NH}_{3}^{+}+\mathrm{HCO}_{3}^{-}
\end{gathered}
$$

These carbamate and bicarbonate species diffuse at a rate higher than $\mathrm{CO}_{2}$ molecules and dissociated into $\mathrm{CO}_{2}$ and water at the permeate side due to the reversibility of the reaction. The behavior is not observed for other gases such as $\mathrm{CH}_{4}$ and $\mathrm{N}_{2}$ because these non-polar gases do not interact with $\mathrm{OH}$ and amine groups. With this unique advantage, amine functionalization can be performed on the nanofiller to improve the facilitated transport and activated diffusion of $\mathrm{CO}_{2}$ in the nanocomposite membrane. For example, amine functionalization of MOF is known as an effective strategy to enhance $\mathrm{CO}_{2}$ affinity and amine-functionalized silica exhibits exceptional $\mathrm{CO}_{2}$ sorption capacities due to the presence of high amine functionalities on the pore surface. $\mathrm{CO}_{2}$ adsorption isotherm investigation revealed that $\mathrm{CO}_{2}$ molecules adsorb better on the amine-functionalized nanoparticles compared to the pristine one due to the strong and effective nucleophile reaction between $\mathrm{CO}_{2}$ and amine groups than with hydroxyl groups [134]. It has also been observed that the MMM embedded with higher loading of aminated nanofiller showed higher solubility that can lead to the higher $\mathrm{CO}_{2}$ permeability due to the higher number of effective amine sites to interact with $\mathrm{CO}_{2}$ molecules [135].

\section{Surface Modifications of Nanomaterials-The Strategies and Performances}

Surface modification of nanofillers used in $\mathrm{CO}_{2}$ gas separation nanocomposite membrane has become a widely adopted strategy for the following reasons: (i) it reduces agglomeration of nanofiller; (ii) it improves polymer-nanofiller compatibility; and (iii) it introduces reactive/functional groups to promote the permeation or selectivity towards $\mathrm{CO}_{2}$ molecules. Surface modification of nanomaterials prior to their direct usage as nanofiller is a feasible and convenient approach as the surface of the commonly used nanofillers such as graphene nanosheets, metal oxide nanoparticles and MOF exhibit surface chemistry which can be readily functionalized. Surface modification of nanomaterials can be accomplished in physical and chemical means through covalent and non-covalent functionalization. Covalent modification involves the formation of bonding between the nanomaterials and the chosen functional groups [136]. The transfer of electrons and formation of new bondings can drastically and permanently affect the intrinsic properties of the nanomaterials. On the other hand, non-covalent functionalization depends on the physical interaction through intermolecular forces such as $\pi-\pi$ interactions, van der Waals force and hydrogen bonding [137]. The choices of approach and functionalization agents used for the nanofiller modification depend on several factors, including the purpose of modifications, the surface reactivity/inertness of the pristine nanomaterials and the complexity of the modification routes. In the following sections, the surface modification strategies of various nanofillers and the corresponding $\mathrm{CO}_{2}$ gas separation performances of the nanocomposite membranes are reviewed. 


\subsection{Silane Functionalization}

Organisilane coupling agents such as aminopropyl triethoxysilane (APTES) have been commonly used as reactive primers to improve the surface compatibility of nanomaterials and polymer due to its effectiveness and simplicity. Endowed with both organic and inorganic functionalities, a silane coupling agent acts at the organic polymer-inorganic nanofiller interface to facilitate the interfacial contact. The structure of a silane coupling agents is represented as $(R O)_{3}-S i-R^{\prime}-X$, where $X$ is an organofunctional group, $\mathrm{R}^{\prime}$ is a small alkylene linkage, and $\mathrm{RO}$ is a group such as an alkoxy group. Alkoxy silane is the most popular silane and it is commercially prepared with one, two or three alkoxy groups. The alkoxy is reactive towards the nanofillers with inorganic properties while the organofunctional groups interact with the polymer matrix through the formation of strong bond [138,139]. Silane grafting is particularly suitable for nanofillers with abundant surface hydroxyl groups and the stable oxane bonds can be formed between the hydroxyl groups and silane compound. Figure 2 illustrates the process of silanization on a nanofiller surface. In brief, the silane agent first hydrolyzes in solution to form reactive silanol. At the interphase, the silanol groups readily react with $-\mathrm{OH}$ attached to the surface of nanomaterials. Once adhered to the nanomaterial surface, the silane agent undergoes self-polymerization to form covalent Si-O-Si linkages. The alkyl groups take part in covalent reaction or physical interaction such as hydrogen bonding or polymer interpenetrating network with the interfacial polymer chains [140]. Besides improving the interfacial interaction, the grafting also improves the dispersion ability of the nanofiller in a wide range of organic solvents. The structure of organosilane can be feasibly engineered with various functional groups to perform a specific function. For example, aminosilane can grant the grafted nanofiller with high affinity towards $\mathrm{CO}_{2}$ due to the presence of amino groups [141].

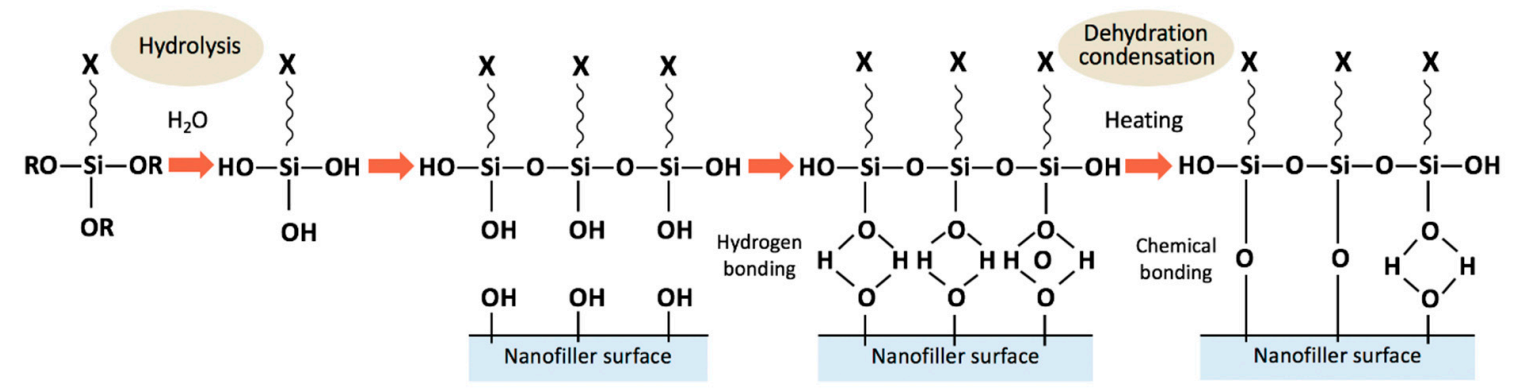

Figure 2. Schematic illustration of stable linkages between silanol group of coupling agent and surface hydroxyl groups of nanofillers.

Silane grafting can be performed by two main routes: (i) direct addition of the silane coupling agent into the polymer dope containing polymer, solvent and nanofillers; and (ii) reaction of silane coupling agent with nanofiller under specific condition prior to the mixing with polymer dope [142]. The reaction conditions and parameters must be carefully controlled as they affect the effectiveness of the grafting and interfacial properties. The parameters involved in silanization include the type and concentration of the silane coupling agent, the solvent used as grafting medium and the temperature and duration of the process. A prolonged reaction with a highly concentrated silane agent results in the formation of thick and multilayer polymerized silane network on the surface. At high concentration, the silane coupling agent tends to chain on the nanofiller and form a rigidified interfacial phase. Excessive amount of silane coupling agent may partially block the pores of nanofillers which in turn reduces the surface area and micropore volume. A silane coupling agent consisting of a methoxy group is favorable over one with an ethoxy group as the former can be hydrolyzed more readily and the structure is subjected to less steric hindrance [143]. The extent of silane polymerization depends on the rate of hydrolysis and the organic substituents of silane coupling agent. The rate of hydrolysis and condensation of the silane coupling agent should be controlled to obtain enough hydroxyl groups for optimal bonding effects. The use of monoalkoxy silane reduces the tendency of pore blockage 
compared to trialkoxy silanes but the latter could form a more stable grafting to the corresponding monoalkoxy silanes. Compared to silane with monoalkoxy and dialkoxy groups, trialkoxy silane forms the highest number of siloxane bonding with the adjacent silane molecules and also with the nanofiller surface.

Silane grafting has been performed on Zeolite $\mathrm{T}$ using three types of silane agents, namely (3-aminopropyl)trimethoxysilane (APTMS), N-(2-aminoethyl)-3-aminopropyl-trimethoxysilane (AAPTMS) and 3-(2-(2-aminoethylamino) ethylamino) propyltrimethoxysilane (AEPTMS) with monoamine, diamine and triamine group, respectively [144]. Zeolite-T modified with AAPTMS and AEPTMS showed better polymer-nanofiller interfacial adhesion compared to that of modified with APTMS. The observation was attributed to the formation of more stable aminosilane-derived layers on Zeolite $\mathrm{T}$ surface with silane agents containing diamine and triamine groups. Besides improving the surface interaction at interface, the silane modified Zeolite T disrupted the chain packing of the polymer phase without forming unselective voids. The AEPTMS modified Zeolite T particles increased the free volume and number of accessible cavities for the transport of $\mathrm{CO}_{2}$. The polarity of grafting solvent affects the homogeneity of silane grafting. Polar solvent such as alcohol increases the mobility of silane groups hence allowing more uniform distribution of the silane compounds on the nanofiller surface [90]. The polarity of grafting solvent also affects the penetration and adsorption or silane coupling agent within the interlayer spaces of layered nanofillers such as nanoclay and GO. The surface hydroxyl groups of these layered structures form stronger hydrogen bonding with polar solvent and induce the penetration of silane agent into the interlayer space [145]. Junaidi et al. modified SAPO-34 zeolite using APTMS in isopropyl alcohol and ethanol [143]. The more polar ethanol facilitated the grafting process and offered better adhesion between the APTMS grafted SAPO-34 and PSf polymer host compared to isopropyl alcohol. While both modified SAPO-34 showed high affinity towards $\mathrm{CO}_{2}$ which in turn increased the permeability and selectivity of the PSf/SAPO-34 MMM, the SAPO-34 grafted with ethanol as grafting solvent rendered the MMM with higher $\mathrm{CO}_{2} / \mathrm{N}_{2}$ and $\mathrm{CO}_{2} / \mathrm{CH}_{4}$ selectivities. Hydrophobic fluoroalkyl silane $1 \mathrm{H}, 1 \mathrm{H}, 2 \mathrm{H}, 2 \mathrm{H}$-perflourodecyltriethoxysilane (HFDS) as also used by Junaidi et al. to modify SAPO-34 prior to the preparation of PSf/SAPO-34 for biogas upgrading [146]. The improved hydrophobicity reduced the water sorption affinity of SAPO-34, hence minimizing the tendency of nanofiller pore blockage and competitive moisture adsorption in the MMMs during the separation process.

Zhang et al. prepared Pebax-based MMM incorporated with different loading of APTES modified GO [121]. Through a facile ultrasonic-assisted functionalization method, the grafting of APTES modified the surface morphology and interlayer spacing of GO. The exfoliation of GO was evident where a more rigid surface with fewer wrinkles was observed. The insertion of APTES molecules at the interlayer enlarged the interlayer spacing of GO. The good interfacial compatibility was achieved with the partial interpenetration of flexible rubbery polymer chain into the silane Si-O-Si network. The interpenetration further created more fractional free volume within the polymer structure for molecular transport. Taking advantage of the amino groups, a facilitated transport pathway was also constructed along the Pebax-GO interface. At the same $0.7 \mathrm{wt} \%$ loading of nanofiller, the MMM incorporated with APTES functionalized GO achieved $\mathrm{CO}_{2}$ permeability and $\mathrm{CO}_{2} / \mathrm{CH}_{4}$ selectivity that were $55 \%$ and $33 \%$ higher than that of incorporated with pristine GO, respectively.

\subsection{Amine Functionalization}

Amine functionalization is the process by which amine groups are introduced into/onto a material [147-150]. It is a common and facile nanofiller modification process to impart adsorption capacity that is specific towards $\mathrm{CO}_{2}$. For instance, the introduction of amine groups into the linkers in MOF leads to preferential absorption of mildly acidic $\mathrm{CO}_{2}$ [44]. Amine functionalization of UiO-66 is performed to obtain $\mathrm{UiO}-66-\mathrm{NH}_{2}$ that exhibits strong $\mathrm{CO}_{2}$ absorption capacity due to the $\mathrm{CO}_{2}$-philicity of the $\mathrm{Zr}$ metal cluster bound hydroxyl ground and amino groups from organic linker [151]. Similarly, the presence of accessible amine group on the linker of $\mathrm{NH}_{2}-\mathrm{MIL}-125$ makes it a promising candidate for 
$\mathrm{CO}_{2}$ separations $[152,153]$. Amine functionalization of nanofiller for $\mathrm{CO}_{2}$ separation can be performed through three major techniques: impregnation, cocondensation and post-synthesis grafting using various amine agents [154]. Impregnation involves the physical attachment of amine groups on the surface and inside the nanomaterial pores. Despite the convenience and high efficiency of this technique, the loaded amine groups tend to conglomerate and can easily detach from the modified surface. The transport of $\mathrm{CO}_{2}$ to active site is also limited due to the diffusion hindrance [155]. Both cocondendation and grafting involve chemical functionalization of amine groups. The amine groups are chemically tethered on the nanofiller surface through in-situ or post-synthesis modification. In the former, amine groups are covalently bound to the hydroxyl-rich surface by substituting the amine group into the framework structure of the nanofiller [156]. The latter functionalization takes place when a reaction occurs between the hydroxy groups of nanofiller and the amine group $[157,158]$. The chemical techniques enable uniform distribution of the amine functional groups without pore blocking while maintaining the stability of the functionalized groups throughout the separation process. It should be noted that the amine-containing groups/chain may attach to the undesirable surface during the grafting process; hence, not all amine sites are available to react with $\mathrm{CO}_{2}$ molecules. Therefore, the total number of amine sites has to be calculated through elemental characterization or back titration analysis to determine the efficiency of amination.

Polymeric amines are polymers bearing amine moieties in their backbone or side chains. Owing to their high amine content, polymeric amines have been widely used in the amination of nanofillers. Polyaniline (PANI)-decorated halloysite nanotube (HNT) has been prepared to enhance $\mathrm{CO}_{2}$ separation of sulfonated poly(ether ether ketone) (SPEEK)-based MMM [159]. As shown in Figure 3a, in-situ polymerization technique was employed to modify the inner, outer and inter-layer spaces as well as the crystal defects and edges of the multilayer tubular nanofiller structure with secondary amine carriers of PANI. The aniline monomers adsorbed on the reactive sites of HNT through electrostatic interaction or hydrogen bonding and then polymerized to form polyaniline over the HNT surface. PANI was attached along the lumen of HNTs, forming a high-speed facilitated transport channels with abundant amine groups for $\mathrm{CO}_{2}$. This PANI offered molecular sieving and the reversible acid-base reaction to facilitate the transport of $\mathrm{CO}_{2}$, hence enhanced the selectivity. The SPEEK-based MMM incorporated PANI coated HNT exhibited long-term performance stability with $\mathrm{CO}_{2}$ permeability and $\mathrm{CO}_{2} / \mathrm{N}_{2}$ selectivity of 1250 Barrer and 82, respectively, as shown in Figure $3 \mathrm{~b}$.

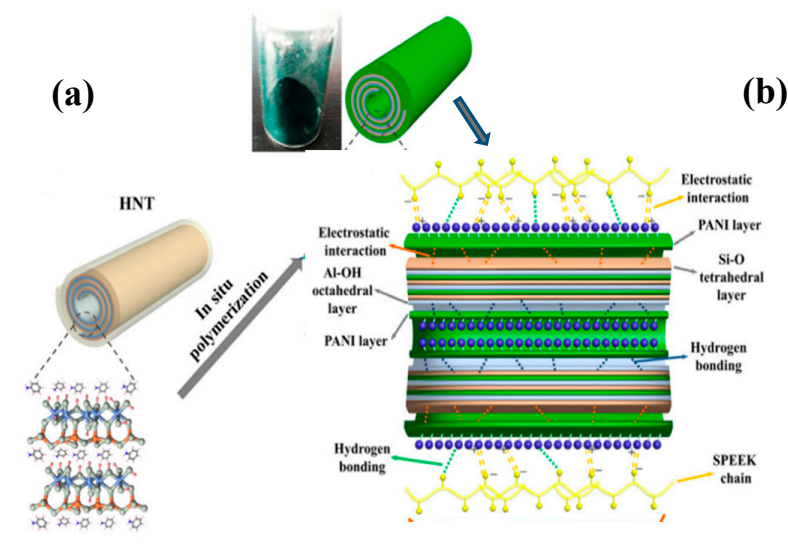

(b)

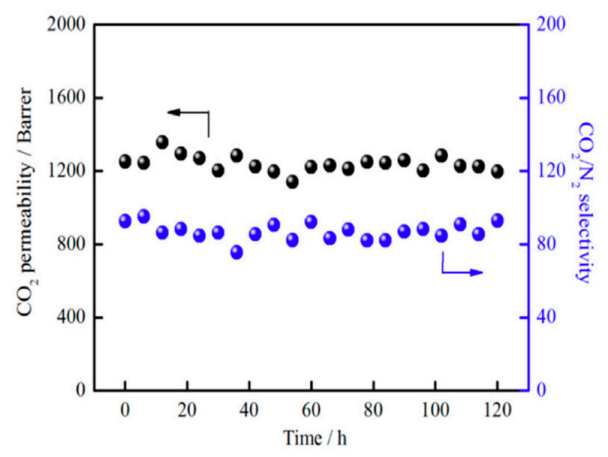

Figure 3. (a) Schematic presentation of the modification of PANI modified HNT and the interaction between SPEEK and nanofiller. (b) Long-term $\mathrm{CO}_{2} / \mathrm{N}_{2}$ separation performance stability of SPEEK incorporated with $0.9 \mathrm{wt} \%$ PANI modified HNT [160].

Suhaimi et al. evaluated $\mathrm{CO}_{2} / \mathrm{CH}_{4}$ separation performance of $6 \mathrm{FDA}$-durene polyimide-based MMM containing ZIF-8 functionalized with amine groups [160]. The functionalization was carried out using APTMS, N-[3-(dimethoxymethylsilyl)propyl ethylenediamine (AAPTMS) and AEPTMS to 
represent mono-, di- and triamine groups, respectively. Although all MMMs prepared in this study showed improved $\mathrm{CO}_{2}$ permeability in the range of $1.6-67 \%$ and $\mathrm{CO}_{2} / \mathrm{CH}_{4}$ selectivity in the range 56.5-224.0\%, relative to the neat PI membrane, the MMM containing $0.5 \mathrm{wt} \%$ AAPTMS-functionalized ZIF-8 exhibited the highest $\mathrm{CO}_{2}$ permeability and $\mathrm{CO}_{2} / \mathrm{CH}_{4}$ ideal selectivity of 825 Barrer and 26.2, respectively. While all amine-functionalized ZIF-8 demonstrated better dispersion and showed better affinity for $\mathrm{CO}_{2}$, the ZIF-8 functionalized with diamine offered the most significant increment, primarily due to the steric hindrance effect of hindered amine, which enhanced the $\mathrm{CO}_{2}$ transport. $\mathrm{TiO}_{2}$ prepared by solvothermal method was one-step modified with polyethyleneimine (PEI) using polydopamine (PDA) as bridging agent [161]. Higher $\mathrm{CO}_{2}$ adsorption capacity was observed in the amine-modified $\mathrm{TiO}_{2}$, which can be attributed to the synergy effect between the porosity and amine-doped sites. During the preparation of Pebax-based MMM, the amine and hydroxyl groups on the PEI and PDA favorably interacted with the polymer chains and improved the compatibility between the two phases. The PEI with higher molecular weight, i.e., longer polymer chain, has a detrimental effect on the $\mathrm{CO}_{2} / \mathrm{N}_{2}$ selectivity due to the hindered $\mathrm{CO}_{2}$ diffusion. The introduction of PEI-functionalized $\mathrm{TiO}_{2}$ substantially enhanced the $\mathrm{CO}_{2} / \mathrm{N}_{2}$ selectivity of the $\mathrm{MMM}$ but the $\mathrm{CO}_{2}$ permeability was decreased compared to that of with pristine $\mathrm{TiO}_{2}$ at the same loading. Nevertheless, the MMM incorporated with $3 \mathrm{wt} \%$ aminated $\mathrm{TiO}_{2}$ transcended the 20008 Robeson upper bound with its highest $\mathrm{CO}_{2} / \mathrm{N}_{2}$ selectivity of 101 and $\mathrm{CO}_{2}$ permeability of 67.7 Barrer.

As-synthesized GO can be readily grafted with amine moieties due to the presence of carboxylic acid ethylene oxide and primary amine groups on the surface. GO nanosheets have been grafted with cysteine, a sulfur containing amino acid, in the presence of dopamine (DA) for the preparation of SPEEK/GO MMM [162]. The water uptake, $\mathrm{CO}_{2}$ solubility and diffusivity of the cysteine grafted GO increased compared to that of pristine GO due to the more favorable conversion of $\mathrm{CO}_{2}$ to bicarbonate, hence leading to increased $\mathrm{CO}_{2}$ permeability. The acid-base interactions between amino acid and sulfonic moieties of SPEEK polymer matrix also promoted interfacial adhesion between GO and SPEEK. Ge et al. prepared aminated GO using ethylenediamine (EDA), which was then used as nanofiller of in-situ polymerized PI-based MMM [163]. Strong interfacial interaction was observed between the aminated GO and the polymer chains of PI. The intercalation of PI chains with aminated GO disrupted the crystalline lattice and increased the polymer intersegmental spacing. As a consequence of the sieving effect of $\mathrm{GO}$ nanosheets and the affinity of $\mathrm{CO}_{2}$ molecules towards aminated $\mathrm{GO}$, the permeability of $\mathrm{CO}_{2}$ increased more profoundly than $\mathrm{N}_{2}$, hence increasing the corresponding $\mathrm{CO}_{2} / \mathrm{N}_{2}$ selectivity has been significantly improved. Mohammed et al. performed amination of reduced GO (rGO) via Bucherer reaction [164]. The amine chain expanded the interlayer spacing of rGO to 0.348 $\mathrm{nm}$, which is between the kinetic diameter of $\mathrm{CO}_{2}(0.34 \mathrm{~nm})$ and $\mathrm{CH}_{4}(0.38 \mathrm{~nm})$, to render additional sieving separation feature to the rGO. The nanocomposite membrane with aminated rGO incorporated Pebax selective layer demonstrated improved $\mathrm{CO}_{2} / \mathrm{CH}_{4}$ by $14 \%$ due to the high $\mathrm{CO}_{2}$ sorption nature of grafted amine groups and polar functional groups readily available on the rGO. However, due to the impermeable nature of GO, the permeability of the nanocomposite membrane has been compromised.

\subsection{Polymer Grafting and Wrapping}

Polymer can be non-covalently and covalently attached on the surface of nanofiller [165-168]. The non-covalent interaction of polymer and nanofillers is established through hydrogen bonding as well as electrostatic, $\pi-\pi$ and hydrophobic interactions. The interactions are adequately strong to improve the dispersion of nanofiller in solvent and polymer dope during membrane preparation [169]. The wrapping of azomethine on CNT could overcome the van der Waals forces among the tubes and lead to the debundling of the nanotube to form individual tubes that well were dispersed in solvents of different polarity [170]. The major advantage of polymer wrapping or impregnation is their non-destructive nature and minimum effects on the microstructure of the modified nanofiller. At higher nanofiller loading, the non-covalent bond may no longer be sufficient to sustain the compatibility between the two phases. Therefore, covalent grafting is needed for stronger and more stable interaction 
between the nanofiller and polymer chains. Covalent modification of nanofiller with polymers can be performed through grafting-to and grafting-from approaches to form strong chemical bonds between nanofiller and long polymer chains [171]. Grafting-to technique involves the reaction of the functional groups of nanofiller with the pre-formed polymers carrying terminal functional groups that are compatible to those of the nanofiller. Although a wide range of polymers are available for grafting-to functionalization, the major limitation of grafting-to technique is the low coverage of nanofiller surface by the polymers owing to the significant steric hindrance effect of the neighboring polymers. Grafting-from approaches offer greater flexibility as they involve the in-situ polymerization of the monomer immobilized on the nanofiller surface $[172,173]$. While the highly reactive monomers allow a more efficient and versatile polymer grafting, the control of reaction conditions and degree of polymerization can be a cumbersome task.

Wrapping of biomacromolecules such as PDA, chitosan and nucleic acid on the nanofillers allows bio-inspired polymer-nanofiller interface design. Particularly, the mussel inspired chemistry of PDA leads to versatile application of PDA to modify all kind of material surfaces in a well-controlled way at molecular level [174]. Wang et al. coated a thin layer of PDA on ZIF-8 by immersing the as-synthesized nanofiller in an alkaline DA medium in which the thickness of the PDA was controlled by manipulating the immersion time [175]. The PDA enhanced the compatibility between ZIF- 8 and Tröger's-based PIM by forming hydrogen bonding between the secondary or primary amine groups of PDA and the tertiary amine found in the Tröger's-based polymer chains. The prolonged coating duration up to $5 \mathrm{~h}$ formed think PDA layer that was more effective in improving the compatibility between ZIF-8 and PIM as the formation of interfacial voids and defects was greatly suppressed. Besides reinforcing the polymer by improving its mechanical stability, the PDA coated ZIF-8 also essentially increased the selectivity of $\mathrm{CO}_{2} / \mathrm{N}_{2}$ and $\mathrm{CO}_{2} / \mathrm{CH}_{4}$ gas pairs. Venna et al. emphasized the importance of finding a well-matched nanofiller and polymeric modifier pair by assessing the compatibility between Matrimid and UiO-66- $\mathrm{NH}_{2}$ which was surface-modified with polymers containing phenyl acetyl, decanoyl acetyl and succinic acid functional groups [126]. These aromatic, aliphatic and acid-moieties ligands were reacted with $\mathrm{UiO}-66-\mathrm{NH}_{2}$ through direct acyl chloride-amine condensation or acid-amine condensation reactions. The phenyl acetyl group and decanoyl acetyl group were dominantly staying on the external surface of UiO-66- $\mathrm{NH}_{2}$ as the diffusion into the internal cavities was restricted by their large molecular size. On the other hand, the smaller succinic acid group diffused into the internal amino sites, which in turn reduced the surface area of the nanofiller. The Matrimid-based MMM incorporated with phenyl acetyl-functionalized $\mathrm{UiO}-66-\mathrm{NH}_{2}$ was refrained from visible sieve-in-a-cage morphology or cavity, indicating a strong interaction has been established between Matrimid and the post modified UiO-66- $\mathrm{NH}_{2}$. As illustrated in Figure 4, the aromatic group and imide groups of Matrimid could interact with phenyl acetate functionalized UiO-66- $\mathrm{NH}_{2}$ through $\pi-\pi$ stacking and hydrogen bonding, respectively.

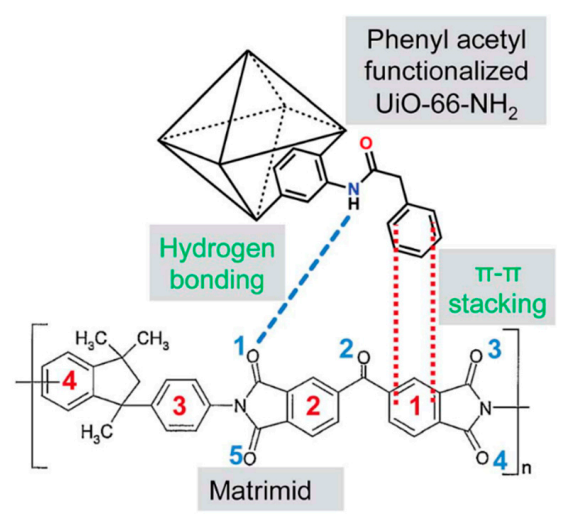

Figure 4. Schematic illustration of the interactions between the Matrimid ${ }^{\circledR}$ polymer and phenyl acetyl functionalized $\mathrm{UiO}-66-\mathrm{NH}_{2}$ through $\pi-\pi$ stacking and hydrogen bonding [126]. 
$\mathrm{Xu}$ et al. functionalized poly(ethylene glycol) diglycidyl ether (PEGDE) onto UiO-66- $\mathrm{NH}_{2}$ so that the modified nanofiller could be crosslinked with PVAm polymer [176]. PEGDE carries reactive groups to form covalent bonds between UiO-66- $\mathrm{N}_{2}$ and PVAm. As depicted in Figure 5a, while one end of PEGDE reacted with the amino group of $\mathrm{UiO}-66-\mathrm{NH}_{2}$, another epoxy end group was retained to crosslink with the amino group on the polymer chain of PVAm. The crosslinking was evidenced by the formation of new bonding such as $\mathrm{C}-\mathrm{O}-\mathrm{C}$ and $\mathrm{Zr}-\mathrm{O}$. The coating solution of UiO-66- $\mathrm{NH}_{2}$-PEGDE-PVAm was then coated on PSf substrate to form a multilayer nanocomposite membrane for $\mathrm{CO}_{2}$ separation, as shown in the scheme in Figure 5b. The improved the interfacial compatibility between PEGDE-crosslinked UiO-66- $\mathrm{NH}_{2}$ and PVAm enabled the incorporation of nanofiller up to $28.5 \mathrm{wt} \%$ while maintaining good dispersion. Compared to composite membrane with neat PVAm, UiO-66- $\mathrm{NH}_{2}$ incorporated nanocomposite membrane exhibited better gas separation performance due to the enhanced diffusion transport through MOF channels and enhanced facilitated transport with more amino groups. On the premise of these features, the PVAm nanocomposite membrane with PEGDE bridging linker has additional advantages, i.e., enhanced affinity towards $\mathrm{CO}_{2}$ molecules rendered by ether oxygen group containing PEGDE and improved compatibility to suppress the formation of interfacial voids. The $\mathrm{CO}_{2}$ permeance of crosslinked and non-crosslinked nanocomposite membranes were 1295 and $989 \mathrm{GPU}$, which were 2.42 and 1.85 times higher than that of neat composite membrane, respectively. The $\mathrm{CO}_{2} / \mathrm{N}_{2}$ selectivity of crosslinked nanocomposite membranes was improved by $12 \%$ with respect to the non-crosslinked counterpart.

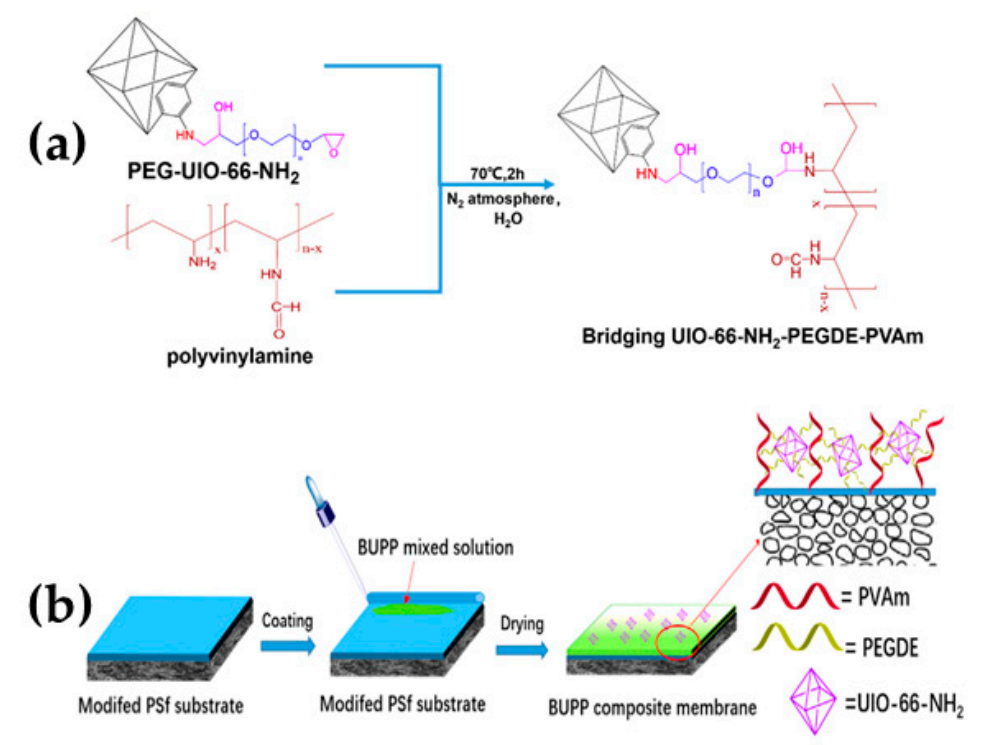

Figure 5. (a) Schematic illustration of covalent interaction between PEGDE modified $\mathrm{UiO}-66-\mathrm{NH}_{2}$ and PVAm; and (b) preparation of nanocomposite membrane [174].

Wang et al. engineered the interfacial properties between $\mathrm{PI}$ and $\mathrm{UiO}-66-\mathrm{NH}_{2}$ with covalently grafted PI brushes [174]. As shown in Figure 6a, the reactive amino group containing surface of UiO-66- $\mathrm{NH}_{2}$ was primed using 4,4'-oxydiphthalicanhydride (ODPA), followed by the polymerization of 2,4,6-trimethyl-m-phenylenediamine (DAM) to form uniform PI brush with thickness approximately $5-10 \mathrm{~nm}$. Subsequently, in-situ chemical imidization was performed to obtain the final PI-based MMM. The decoration of the MOF surface with polymer compatibilizer that has identical composition as the polymer host promoted nanofiller dispersion and interfacial adhesion. The strong interfacial adhesion induced by the PI brush improved the nanocomposite membrane ductility by $472 \%$ and reduced interfacial tearing under shear force, as witnessed in the ultrathin slice cross-sectional images of the membranes in Figure 6b. The MMM incorporated with PI-decorated UiO-66- $\mathrm{NH}_{2}$ achieved increased $\mathrm{CO}_{2}$ permeability and selectivity with increasing nanofiller loading. The improvement relative to neat PI was more significant compared to the one without PI brush decoration. The MMM 
also witnessed $\mathrm{CO}_{2} / \mathrm{CH}_{4}$ separation surpassing the 1991 upper bound and approaching the 2008 upper bond. The $\mathrm{CO}_{2}$ plasticization was also mitigated owing to the decreased matrix chain mobility by the physical crosslinking nodes that connected the neighboring PI chains.

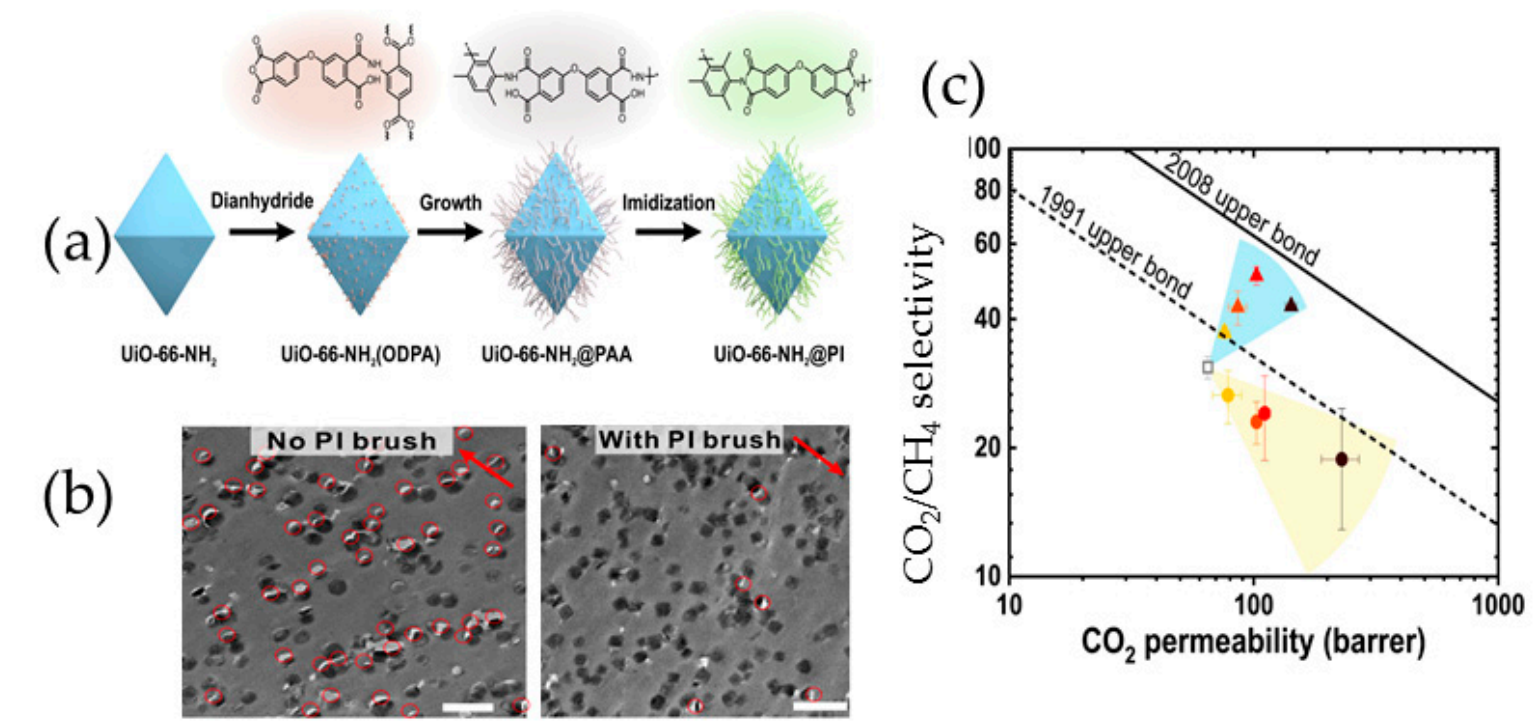

Figure 6. (a) Schematic illustration of step-wise preparation of UiO-66- $\mathrm{NH}_{2}$ decorated with PI brushes; (b) cross-sectional images of ultrathin slices of MMM (i) without PI brush and (ii) with PI brush (scale bar $500 \mathrm{~nm}$ ); and (c) plot of $\mathrm{CO}_{2}$ permeability versus $\mathrm{CO}_{2} / \mathrm{CH}_{4}$ selectivity of the neat PI (opened square), PI with PI brushes decorated UiO-66- $\mathrm{NH}_{2}$ (closed triangle) and PI with pristine UiO-66- $\mathrm{NH}_{2}$ (closed circle) [175].

\subsection{Ionic Liquid}

Ionic liquids (IL) are salt-like ionic materials that exist in liquid form below $100^{\circ} \mathrm{C}$. IL haev been used as an additive of polymeric membrane to increase the polymer segmental flexibility [177-179]. IL can modify the hydrogen bonding in amino-containing polymer chains, consequently making the amino groups available as $\mathrm{CO}_{2}$ absorbing sites [180]. The direct addition of IL into the polymer dope during processing is not always a favorable approach as the IL might occupy the free volume and reduce the gas diffusion through the polymer $[47,181]$. The post-impregnation of MMM with IL can also be carried by immersing the pre-formed membrane into IL solution [182,183]. However, the charge attraction between IL and membrane surface may not be sufficiently strong to sustain a firm IL attachment. Another interesting way to harness the advantage of IL is by impregnating them onto the surface of nanofiller. The charged ions carried by IL can form electric double layer and establish electrostatic interaction with the nanofiller, and help to improve the dispersion of nanofiller when sufficient amouny of IL is used to completely cover the surface of nanofiller [184]. The IL components also induce plasticization effect to enable more flexible interaction of the polymer chains with the IL modified nanofiller and improved processability [177,185].

IL such as 1-ethyl-3-methylimidazolium bis(trifluoromethylsulfonyl)imide ([Emim][Tf $2 \mathrm{~N}])$ and 1-butyl-3-methylimidazolium bis(trifluoromethanesulfonyl)imide ([Bmim][Tf $\left.f_{2} \mathrm{~N}\right]$ ) exhibit high $\mathrm{CO}_{2}$ solubility thus can been favorably used as interfacial binder and gas selective sealing agent to suppress voids formation at the polymer-nanofiller interphase. The effectiveness of ionic liquid to serve this purpose is dominantly controlled by the anion functional groups. Brennecke et al. observed that higher solubility of $\mathrm{CO}_{2}$ could be achieved with $\left[\mathrm{Tf}_{2} \mathrm{~N}\right]^{-}$anion containing fluoroalkyl and $\mathrm{S}=\mathrm{O}$ groups compared to tetrafluoroborate $\left[\mathrm{BF}_{4}\right]^{-}$anion which lacks of functionality [186]. The molecular chain length of cations also affects the ionic liquid, but in a smaller extent. It is generally observed that a longer cation chain renders higher $\mathrm{CO}_{2}$ solubility. As ionic liquid could act as a gas carrier agent besides improving the interfacial compatibility, the gas separation of MMM incorporated with IL 
impregnated nanofiller is also governed by the gas solubility of the IL. Different modification strategies have been accomplished to introduce IL into the nanocomposite membranes. The direct immersion of nanofiller in IL dissolved in alcohol dominantly impregnate IL on the nanofiller surface, hence the major function is to improve filler-polymer interface in the MMM [187]. Meanwhile, the more sophisticated in-situ synthesis technique would allow the confinement of IL within the internal pores of the nanofiller [188]. As such, high $\mathrm{CO}_{2}$ solubility and transport can also be facilitated within the nanofiller pores.

$\mathrm{ZnO}$ impregnated with 1-butyl-3-methylimidazolium tetrafluoroborate $\left([\mathrm{Bmim}]\left[\mathrm{BF}_{4}\right]\right)$ has been used as a nanofiller to prepare nanocomposite membrane. The nanocomposite was made up of PEO selective layer and PSf substrate [189]. The IL molecules completely covered the surface of ZnO such that the interface was primarily established between IL and PEO. During $\mathrm{CO}_{2} / \mathrm{N}_{2}$ separation, in addition to the enhanced $\mathrm{CO}_{2}$ solubility and $\mathrm{N}_{2}$ permeation barrier effect rendered by $\mathrm{ZnO}$, the presence of IL further improved the $\mathrm{CO}_{2}$ permeability. As a result, the permeance of $\mathrm{CO}_{2}$ was enhanced from $17 \mathrm{GPU}$ for MMM with pristine $\mathrm{ZnO}$ to $101 \mathrm{GPU}$ for that of with IL-modified ZnO. The effectiveness of three types of ionic liquid, namely $[\mathrm{Emim}]\left[\mathrm{Tf}_{2} \mathrm{~N}\right],[\mathrm{Bmim}]\left[\mathrm{Tf}_{2} \mathrm{~N}\right],[\mathrm{Bmim}]\left[\mathrm{BF}_{4}\right]$, in improving the interaction between 6FDA-durene and ZIF-67 has been evaluated [44]. The cation and anions composition and functional groups of the IL are shown in Figure 7a. The impregnation of IL was performed by dissolving both IL and ZIF-67 in chloroform co-solvent. Chloroform was used to prevent excessive IL diffusion into the ZIF-67 pores. The focused ion beam scanning electron microscopy (FIB-SEM) images in Figure 7b indicates that the interfacial void formation in the MMM incorporated with IL-modified ZIF-67 was greatly suppressed. The observation witnessed the role of IL as interfacial compatibilizer to improve the compatibility between ZIF-69 and 6FDA-durene. The MMM incorporated with [Bmim][BF 4 modified ZIF-67 exhibited the lowest gas permeability among the three MMM because of the presence of excessive IL in the surface pores of ZIF-67. In addition, the long alkyl chain and large structure of the $[\mathrm{Bmim}]\left[\mathrm{BF}_{4}\right]$ blocked the gas diffusion through ZIF channels in a greater extent compared to [Emim][Tf $\left.f_{2} \mathrm{~N}\right],[\mathrm{Bmim}]\left[\mathrm{Tf}_{2} \mathrm{~N}\right]$. This study highlights the fact that, despite the effectiveness of IL layer in reducing the non-selective interfacial defects, IL coating approach may be more appropriate for nanofiller with large opening and pore size.
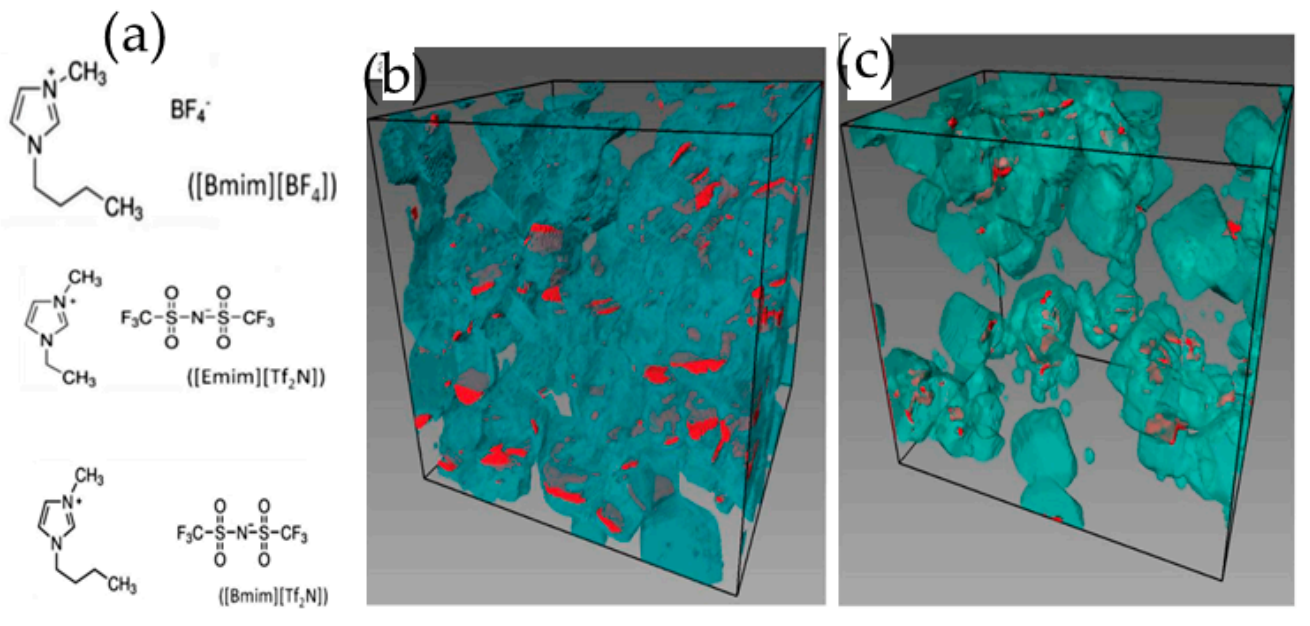

Figure 7. (a) The chemical composition and functional groups of [Bmim][BF4], [Emim][Tf $2 \mathrm{~N}]$ and $[\mathrm{Bmim}]\left[\mathrm{Tf}_{2} \mathrm{~N}\right]$. FIB surface rendered view of MMM incorporated with (b) pristine ZIF-67 and (c) [Bmim][BF4] impregnated ZIF-67 [43].

In another recent work, Ding et al. decorated the surface of LDH nanocage with 1-hexyl-3methylimidazolium bis(trifluoromethylsulfonyl)imide $\left([\mathrm{Hmim}]\left[\mathrm{Tf}_{2} \mathrm{~N}\right]\right)$, prior to the incorporation into Pebax matrix to form $\mathrm{CO}_{2}$ separation MMM [190]. The lamellar and cage-like structure of LDH provides large surface capacity to accommodate more IL not only on the external surface, but also within its internal 
hollow core and interlamellar spacing that has anion exchange stability. The improved interfacial properties of the IL-decorated LDH nanocage and Pebax were reflected by the enhancement in thermal stability and mechanical strength. The polyamide (PA) and PEO blocks of Pebax were highly compatible with IL modified nanofiller in which the former could establish hydrophobic-hydrophobic interaction with the hydrophobic sites of the IL-decorated LDH while the latter could interact with the IL cation. The IL encapsulated at different locations of the nanofiller played important roles in improving the $\mathrm{CO}_{2}$ permeability of the MMM. The $\mathrm{S}=\mathrm{O}$ groups containing IL impregnated on the external surface and in the internal hollow core effectively absorbed $\mathrm{CO}_{2}$ molecules which were then transported by the carbonate carrier in the interlamellar spaces to facilitated fast $\mathrm{CO}_{2}$ transport. The optimal humidified $\mathrm{CO}_{2}$ permeability and $\mathrm{CO}_{2} / \mathrm{CH}_{4}$ selectivity of MMM were reported as 644 Barrer and 34, respectively, with the incorporation of $6 \mathrm{wt} \%$ IL decorated nanofiller.

Amined-based 3-(trimethoxysilyl) propan-1-aminium acetate ([APTMS][Ac]) has been synthesized for the modification of zeolite 4A [47] and ZIF-67 [191] to prepare PSf-based MMM for $\mathrm{CO}_{2}$ separation. The grafting of [APTMS][Ac] on the external surface of zeolite $4 \mathrm{~A}$ took place through the condensation of surface silanol groups. Despite a slight decrease in the surface area and pore volume, the zeolite crystallinity has been conserved in the grafting process. On the other hand, direct immersion has been performed to impregnate [APTMS][Ac] and form a uniform IL layer on the surface of ZIF-67. In both studies, the $\mathrm{CO}_{2}$ solvation was improved with the existence of $\mathrm{CO}_{2}$-affinitive moieties in the IL, i.e., the methoxy moieties of cation and acetate anion, which have provided additional sites for $\mathrm{CO}_{2}$ interaction. With IL modified zeolite loading of $30 \mathrm{wt} \%$, the $\mathrm{CO}_{2} / \mathrm{CH}_{4}$ and $\mathrm{CO}_{2} / \mathrm{N}_{2}$ selectivities were improved 37\% and 43\%, respectively, compared to MMM with pristine zeolite $4 \mathrm{~A}$. With the same loading, the incorporation of IL modified ZIF improved the $\mathrm{CO}_{2} / \mathrm{CH}_{4}$ by $6 \%$ and $190 \%$ compared to that of neat PSf membrane and the MMM with pristine ZIF, respectively.

\subsection{Solvent-Free Nanofluids}

Solvent-free nanofluids are an emerging class of organic-inorganic hybrids which involve the grafting onto a nanoparticle surface brushes of polymers in the form of a canopy. The typical structure of solvent-free nanofluids consists of a nanomaterial core, linker molecules corona and polyether amine canopy, as shown in Figure 8a [192]. Depending on the characteristics of organic materials, the nanofluid system can be prepared in several forms: solvent-free liquid-like nanofluids, solid sorbents or gel-like materials [193]. However, the fluid-like structure is advantageous as the fluidity enables more flexibility in its processing. Figure $8 \mathrm{~b}$ shows the fluidic physical appearance of nanofluid containing CNT core. Although the core can be made from nanomaterials of any dimension or the single, binary or ternary structure of these nanomaterials, the dimension of the core governs the liquid-like behavior of the nanofluid. The structure of the core and canopy can be rationally tuned by incorporating specific functional groups to cater for specific applications. By rendering the unique liquid-like behavior to the nanofiller core, the agglomeration can be significantly minimized. The extended chain architecture imposes steric stability so that the brushed nanofiller can be well dispersed in miscible polymer matrix.

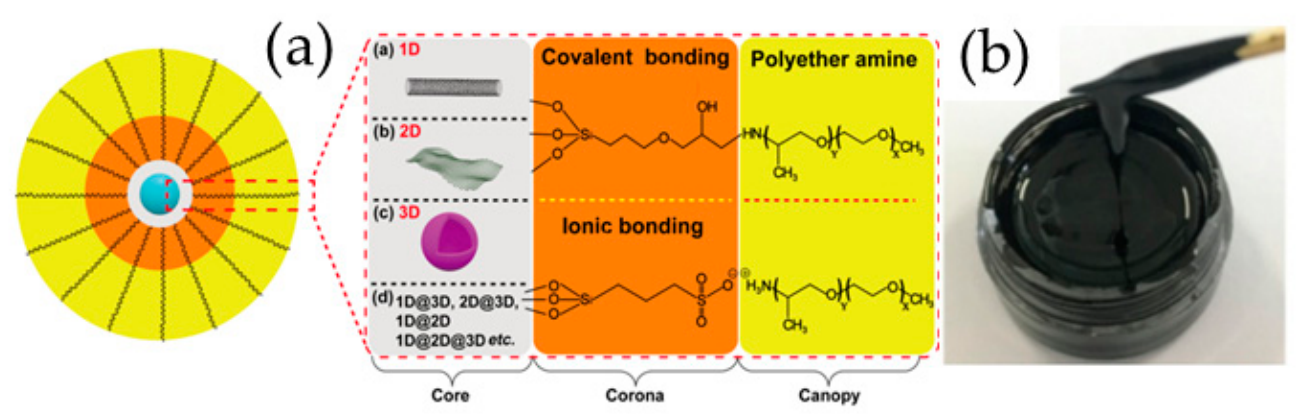

Figure 8. (a) Schematic diagram of solvent-free nanofluids that consist of nanomaterial core, linker corona and polyether amine canopy; and (b) physical appearance of nanofluid containing CNT core [191]. 
The surface modification of nanomaterials into solvent-free nanofluids offers advantages for $\mathrm{CO}_{2}$ capture application. Nanofluid structure is an attractive alternative of amine-based chemical as the canopy of the nanofluid can be tailored to improve gas uptake capacity [194]. Solvent-free MWCNT nanofluid with ionic tethering and polyether amine terminated polymers has been prepared for $\mathrm{CO}_{2}$ capture [195]. The MWCNT nanofluids exhibited higher adsorption capability compared to the corresponding polyether amine and unmodified MWCNTs as the adsorption took place via both chemisorption and physisorption. As the oxygenated and amine functional groups responsible for the $\mathrm{CO}_{2}$ capture capacity, the MWCNT nanofluid grafted with long chain canopy showed increasing $\mathrm{CO}_{2}$ capture capability.

Wang et al. prepared CNTs and GO solvent-free hybrid nanofluids by covalently grafting the nanofillers with polyetheramine in colloidal state at room temperature [193]. The GO and MWCNT nanofluids were then incorporated into Pebax matrix using drop-casting method. The fluidic CNT and MWCNT nanofillers homogeneously dispersed and showed excellent interfacial compatibility with the polymer matrix. No agglomeration was detected even at high nanofiller loading up to $40 \mathrm{wt} \%$. The MMM incorporated with $30 \mathrm{wt} \%$ CNT nanofluid and $15 \mathrm{wt} \%$ GO nanofluid exhibited optimal $\mathrm{CO}_{2} / \mathrm{N}_{2}$ separation of 72 and 56 with $\mathrm{CO}_{2}$ permeability of 332 and 242 Barrer, respectively. The separation of these MMMs was superior to that of neat Pebax membrane owing to the good interfacial properties and the existence of multiple active sites in the nanofiller to promote $\mathrm{CO}_{2}$ separation. Besides the fast diffusion of $\mathrm{CO}_{2}$ through the hollow and nanosheet structure of $\mathrm{CNT}$ and $\mathrm{GO}$, the ether bonds in polyether amine canopy also interacted with $\mathrm{CO}_{2}$ through Lewis acid-base interaction to enhance $\mathrm{CO}_{2}$ transport.

\subsection{Metal Ions}

Besides amine groups, metal ions such as $\mathrm{Ag}^{+}$and $\mathrm{Zn}^{2+}$ ions can also serve as $\mathrm{CO}_{2}$ facilitated transport carrier based on $\pi$-complexation mechanism. Conventionally, metal ions are blended into polymer to form a facilitated membrane with fixed carrier. On the other hand, facilitated membrane with mobile carrier is prepared by incorporating metal oxides or metal nanoparticles directly into ionic liquid. More recently, attempts have been made to introduce metal ions onto the nanofiller before the nanofiller is incorporated into polymer matrix. Matrimid/AgY MMM was prepared by incorporating post-synthesis ion exchanged $\mathrm{NaY}$ into Matrimid [196]. The ion exchange of $\mathrm{NaY}$ in silver nitrate solution to substitute $\mathrm{Ag}^{+}$into the crystal lattice of $\mathrm{NaY}$. A substantial increase in $\mathrm{CO}_{2}$ permeability of Matrimid/AgY MMM compared to Matrimid/NaY was contributed by the $\mathrm{CO}_{2}$ facilitated transport rendered by the $\mathrm{Ag}^{+}$ions located at the external surface and within the apertures. Peng et al. modified GO with $\mathrm{Zn}^{2+}$ ions via DA-bridged complexation reaction [197]. DA can readily self-polymerize into PDA under mild basic condition on the GO nanosheet surface and served as bridging agent to strengthen the interaction between GO nanosheets and $\mathrm{Zn}^{2+}$ ions. The catechol groups of PDA exhibited strong metal ion complexing to facilitate the distribution and uniformity of $\mathrm{Zn}^{2+}$ ions on the nanosheet. The high surface area of GO nanosheets also benefitted the high loading on $\mathrm{Zn}^{2+}$ ions, which was successfully loaded to attain maximum facilitated transport ability. Figure 9a shows the modification procedures of GO, which involved self-polymerization of DA followed by deposition of $\mathrm{Zn}^{2+}$ ions via complexation reaction. As shown in Figure 9b, although the presence of $\mathrm{Zn}^{2+}$ ions did not significantly change the two-dimensional sheet structure of GO, smaller GO nanosheets were formed upon sonication treatment with $\mathrm{Zn}^{2+}$ ions precursor. The gas separation performance of Pebax-based MMM incorporated with GO modified with PDA and $\mathrm{Zn}^{2+}$ ions exhibited drastically enhanced $\mathrm{CO}_{2}$ permeability and $\mathrm{CO}_{2} / \mathrm{CH}_{4}$ selectivity. The anchored $\mathrm{Zn}^{2+}$ ions facilitated the transport of $\mathrm{CO}_{2}$ by forming zinc ions- $\mathrm{CO}_{2}$ complex while $\mathrm{CH}_{4}$ solely transported through solution-diffusion mechanism. The nanosheet with smaller size also allowed better Pebax-GO compatibility. The benchmarking shown in Figure 9c implied that GO decorated $\mathrm{Zn}^{2+}$ ions served as a more promising nanofiller compared to pristine GO and the resultant MMM exhibited separation performance that almost surpass 1991 Robeson upper bound. 

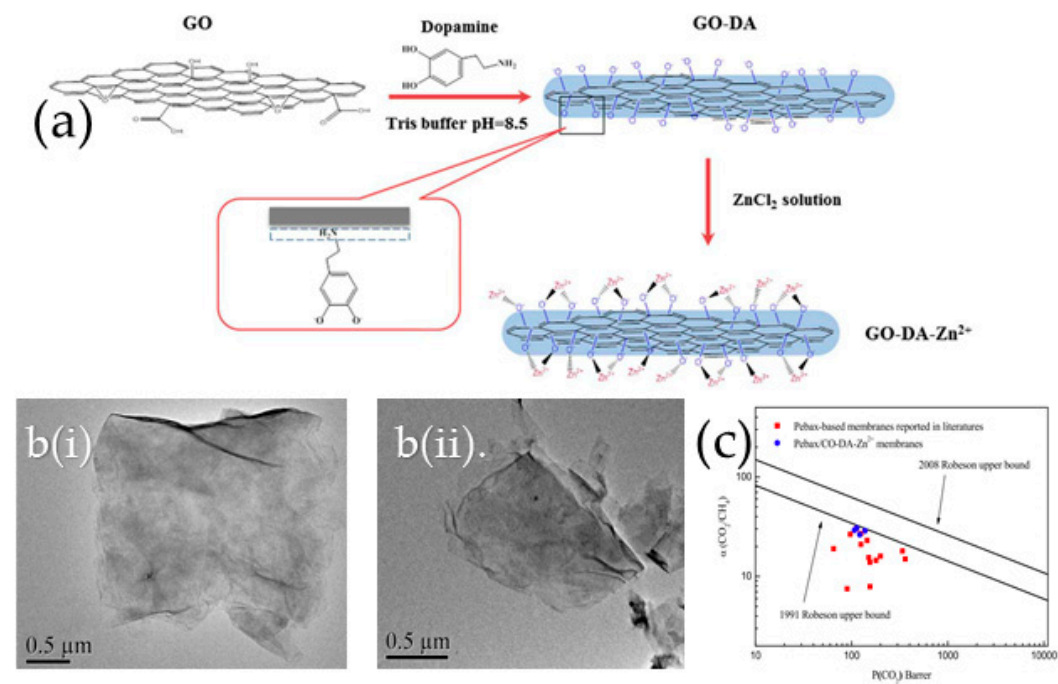

Figure 9. (a) modification procedures of GO which involved self-polymerization DA and followed by deposition of $\mathrm{Zn} 2+$ ions via complexation reaction; (b) morphology of GO/dopamine (i) with and (ii) without Zn2+ ions; and (c) separation performance of Pebax-based MMM incorporated with Zn2+ ions modified GO [196].

\section{Challenges and Future Outlook}

It has been half a century since the first attempt at preparing nanocomposite membrane for gas separation. Despite the advantages offered by inorganic nanomaterials in advancing the properties of polymeric membranes, many attempts made in this area have been unsuccessful or far below expectations. In the development of $\mathrm{CO}_{2}$ separation nanocomposite membranes, there are many critical factors that determine the success of the separation process: the matching of polymer and nanofiller, the interaction between polymer and nanofiller, the preparation and fabrication of membrane, the characteristics of gas mixture to be separated, the interaction between polymer and nanofillers with the gas molecules, etc. Surface modification of nanofiller is an important topic in the development of $\mathrm{CO}_{2}$ separation nanocomposite membranes. Although it is agreed that a substantial number of materials and synthesis approaches are available to prepare numerous nanofillers, the modification of nanofiller provides a less costly option to introduce new or enhance the existing functionalities. The one-pot modification can also be more conveniently carried out rather than synthesizing a new type of nanofiller from scratch. A proper selection of suitable modifying agents and well-planned modification route can simultaneously resolve issues associated to agglomeration and dispersion of nanofiller and compatibility between polymer and nanofiller as well as impart additional $\mathrm{CO}_{2}$ separation functions to the resultant nanocomposite membranes. As reviewed in this article and summarized in Table 1, significant progresses have been made in the modifications of nanofiller and development of nanocomposite membranes for $\mathrm{CO}_{2}$ removal. To facilitate the deployment of nanocomposite membrane for practical industry application, several challenges related to this topic have been identified.

The effects of surface modification on the intrinsic characteristics of nanofillers must be carefully evaluated. Through the current modification approaches, it has been generally observed that the pore volume and BET surface area of the nanofillers have been significantly reduced compared to those of pristine nanofiller. The interesting features of nanofillers that contribute to molecular sieving properties, such as the tunable breathing behaviors of MOF and interlayer space of GO, may be partially or completely altered. Pore blockage or difficulty in determining the modification site are among the several issues that need to be investigated while designing the modification routes. The blockage of these confined environments brings detrimental effects on the intrinsic separation properties of the nanofiller. For example, the excessive penetration of IL into the nanofiller pores 
presents a serious problem as the thick IL coating may interfere with and compromise the gas transport properties. Current surface modification toolkits of nanofiller are still mainly focused on post-synthesis modification. More advanced modification techniques based on bottom-up approaches should be explored. In-situ modification of nanofiller during the synthesis process may be an interesting option to achieve better treatment uniformity and functionalization degree.

Surface modification of nanofiller is always a double-edged sword. While a well-designed modification can remarkably enhance the properties of both nanofiller and the resultant nanocomposite, a poorly controlled modification route may severely damage the structure of nanofillers and deteriorate their intrinsic properties that are desired for nanocomposite membranes. A fundamental understanding on the modification mechanisms is the key to construct desired structural and morphological properties of modified nanomaterials. In light of the conditions of nanofiller surface modification which normally involves wet chemistry that is complex in nature, the control of the modification microenvironment is necessary to achieve the expected outcomes. The optimal conditions may only be attained after countless attempts not only in controlling the experimental parameters, but also the chemicals used. It is also important to point out that it is challenging to strike a balance between the simplicity and effectiveness of the surface modification. Satisfactory modification outcomes are usually achieved through multiple sophisticated modification steps which also consume large amount of chemicals while a relatively simple modification, such as single-step acid oxidation is deemed less effective. Seemingly, more effective techniques and processes are needed to address this concern. Plasma treatment has gained wide attentions for surface modifications as it requires less amounts of chemicals and less complicated processing steps. The versatility of this technique allows chemical functionalization to be performed on almost any surface [198]. Along this line, click chemistry approaches also have great potential in enhancing the surface modification efficiency. Click chemistry adopts the concept based on highly efficient and sustainable chemical reaction to achieve the high yield reaction. Copper-catalyzed azide-alkyne cycloadditions (CuAAC) has been used for the functionalization of such as halloysite nanotube, graphene oxide and silica [199].

With the limitations of direct visualization and characterization, theoretical and simulation studies are important to provide insights on the roles and interactions between the components in nanocomposite membrane. For instance, the change in the modifying agent structure and the behavior of gas molecules when passing through the surface modified nanofiller has yet to be fully characterized. Therefore, the correlation between the surface modified nanofiller and the separation properties of nanocomposites established through modeling studies is imperative to complement the experimental observations. It is very useful to develop a model that can predict the separation performance of the nanocomposite membrane for the purpose of designing a practical surface modification approach. Despite the recent efforts in simulating the gas transport behavior in nanocomposite membranes for $\mathrm{CO}_{2}$ separation [200], the chemical basis of the interaction and bonding between the nanofiller and modifier through computational approach has been scarcely reported. Lastly, the ultimate goal of all forms of research and development is to bring the lab-established technology to the next operation step in industry. For practical application, the large-scale demonstration of the surface modification strategies and their corresponding membrane gas separation performance must be considered. The technological and economical aspects must be carefully assessed at this stage to pave the way for commercialization. 
Table 1. Summary of nanofiller modification and their corresponding gas separation performance.

\begin{tabular}{|c|c|c|c|c|c|c|c|c|}
\hline Polymer & Nanofiller & $\begin{array}{l}\text { Nanofiller } \\
\text { Loading }\end{array}$ & $\begin{array}{c}\text { Surface } \\
\text { Modification }\end{array}$ & $\begin{array}{c}\text { Modification } \\
\text { Agent }\end{array}$ & $\begin{array}{l}\text { Operating } \\
\text { Condition }\end{array}$ & $\begin{array}{l}\text { Gas pair Selectivity } \\
\text { (vol. Ratio) }\end{array}$ & $\mathrm{P}_{\mathrm{CO}_{2}}$ & Ref \\
\hline Ultem 1000 & MIL-53 & $10 \mathrm{wt} \%$ & $\begin{array}{l}\text { Silanation/ } \\
\text { amination }\end{array}$ & APTMS & $\begin{array}{l}5 \text { bar, } 25^{\circ} \mathrm{C} \\
\text { (S) }\end{array}$ & $\mathrm{CO}_{2} / \mathrm{N}_{2}=41$ & $24.1 \mathrm{G}$ & [100] \\
\hline 6FDA-durene & Zeolite T & $1 \mathrm{wt} \%$ & $\begin{array}{l}\text { Silanation/ } \\
\text { amination }\end{array}$ & AEPTMS & $\begin{array}{c}3.5 \mathrm{bar}, 30^{\circ} \mathrm{C} \\
(\mathrm{M})\end{array}$ & $\mathrm{CO}_{2} / \mathrm{CH}_{4}(50 / 50)=22.5$ & $857.7 \mathrm{~B}$ & [144] \\
\hline Pebax 1657 & GO & $0.7 w t \%$ & $\begin{array}{l}\text { Silanation/ } \\
\text { amination }\end{array}$ & APTES & $\begin{array}{c}2 \mathrm{bar}, 35^{\circ} \mathrm{C} \\
(\mathrm{M})\end{array}$ & $\begin{array}{c}\mathrm{CO}_{2} / \mathrm{CH}_{4}(30 / 70)=17.2 \\
\mathrm{CO}_{2} / \mathrm{N}_{2}(20 / 80)=45.2\end{array}$ & $172 \mathrm{~B}$ & [121] \\
\hline SPEEK & GO & $8 w t \%$ & Amination & $\begin{array}{l}\text { Cystine/ } \\
\text { PDA }\end{array}$ & $\begin{array}{c}1 \mathrm{bar}, 25^{\circ} \mathrm{C} \\
(\mathrm{M})\end{array}$ & $\mathrm{CO}_{2} / \mathrm{CH}_{4}(30 / 70)=82$ & $\begin{array}{c}1247 \text { B } \\
(\mathrm{H})\end{array}$ & [162] \\
\hline Matrimid 5218 & UiO-66/GO & $5 \mathrm{wt} \%$ & Amination & - & 3 bar, $25^{\circ} \mathrm{C}$ & $\mathrm{CO}_{2} / \mathrm{N}_{2}=52.0$ & $7.28 \mathrm{~B}$ & [151] \\
\hline PI & GO & $3 \mathrm{wt} \%$ & Amination & EDA & $\begin{array}{l}1 \mathrm{bar}, 25^{\circ} \mathrm{C} \\
(\mathrm{M})\end{array}$ & $\mathrm{CO}_{2} / \mathrm{N}_{2}=38.6$ & $12.3 \mathrm{~B}$ & [163] \\
\hline Pebax & rGO & $4 w t \%$ & Amination & $\begin{array}{l}\text { Bucherer } \\
\text { reaction }\end{array}$ & 4 bar, $25^{\circ} \mathrm{C}$ & $\mathrm{CO}_{2} / \mathrm{CH}_{4}=24$ & $40.8 \mathrm{~B}$ & [164] \\
\hline SPEEK & HNT & $0.9 w t \&$ & Amination & PANI & $1 \mathrm{bar}, 25^{\circ} \mathrm{C}$ & $\mathrm{CO}_{2} / \mathrm{N}_{2}=82$ & $1250 \mathrm{~B}$ & [159] \\
\hline 6FDA-durene & ZIF-8 & $0.5 \mathrm{wt} \%$ & Amination & AAPTMS & 3.5 bar, $35^{\circ} \mathrm{C}$ & $\mathrm{CO}_{2} / \mathrm{CH}_{4}=26.2$ & $825 \mathrm{~B}$ & [160] \\
\hline Pebax 1657 & $\mathrm{TiO}_{2}$ & $3 w t \%$ & Amination & $\begin{array}{l}\text { PEI/ } \\
\text { PDA }\end{array}$ & 0.3 bar, $25^{\circ} \mathrm{C}$ & $\mathrm{CO}_{2} / \mathrm{N}_{2}(50 / 50)=101$ & $67.7 \mathrm{~B}$ & [164] \\
\hline PVAm & UiO-66- $\mathrm{NH}_{2}$ & $28.5 w t \%$ & $\begin{array}{c}\text { Polymer } \\
\text { crosslinking }\end{array}$ & PEGDE & 3 bar, $25^{\circ} \mathrm{C}$ & $\mathrm{CO}_{2} / \mathrm{N}_{2}=91$ & $1295 \mathrm{G}$ & [176] \\
\hline PI & UiO-66-NH ${ }_{2}$ & $17 \mathrm{wt} \%$ & Polymer brush & ODPA & 3.1 bar, $35^{\circ} \mathrm{C}$ & $\mathrm{CO}_{2} / \mathrm{CH}_{4}(20 / 80)=51$ & - & [200] \\
\hline Pebax 1657 & ZIF-8 & $15 \mathrm{wt} \%$ & IL & {$[\mathrm{bmim}]\left[\mathrm{Tf}_{2} \mathrm{~N}\right]$} & $1 \mathrm{bar}, 35^{\circ} \mathrm{C}$ & $\begin{array}{c}\mathrm{CO}_{2} / \mathrm{CH}_{4}=34.8 \\
\mathrm{CO}_{2} / \mathrm{N}_{2}=83.9\end{array}$ & $104.9 \mathrm{~B}$ & [187] \\
\hline PEO & $\mathrm{ZnO}$ & - & $\mathrm{IL}$ & {$[\mathrm{Bmim}]\left[\mathrm{BF}_{4}\right]$} & - & $\mathrm{CO}_{2} / \mathrm{N}_{2}=29.7$ & $35.7 \mathrm{G}$ & [189] \\
\hline Pebax 1657 & LDH nanocage & $6 \mathrm{wt} \%$ & $\mathrm{IL}$ & [Hmim][NTf2] & 2 bar, $25^{\circ} \mathrm{C}$ & $\mathrm{CO}_{2} / \mathrm{CH}_{4}(10 / 90)=34$ & $644 \mathrm{~B}$ & [190] \\
\hline PSf & ZIF-67 & $30 \mathrm{wt} \%$ & $\mathrm{IL}$ & [APTMS][Ac] & 10 bar & $\mathrm{CO}_{2} / \mathrm{CH}_{4}(50 / 50)=67$ & $20 \mathrm{~B}$ & [191] \\
\hline Pebax 1657 & GO & $1 \mathrm{wt} \%$ & $\begin{array}{l}\text { metal ion } \\
\text { decoration }\end{array}$ & $\mathrm{ZnCl}_{2}\left(\mathrm{Zn}^{2+}\right)$ & $\begin{array}{c}2 \text { bar, } 30^{\circ} \mathrm{C} \\
(\mathrm{M})\end{array}$ & $\mathrm{CO}_{2} / \mathrm{CH}_{4}(30 / 70)=28.8$ & $137.9 \mathrm{~B}$ & [197] \\
\hline Matrimid 5218 & $\mathrm{NaY}$ & $15 \mathrm{wt} \%$ & $\begin{array}{l}\text { metal ion } \\
\text { exchange }\end{array}$ & $\mathrm{AgNO}_{3}\left(\mathrm{Ag}^{+}\right)$ & 2 bar, $35^{\circ} \mathrm{C}$ & $\mathrm{CO}_{2} / \mathrm{CH}_{4}=55.7$ & $18.62 \mathrm{~B}$ & [196] \\
\hline
\end{tabular}

Remarks: $\mathrm{S}$, single/pure gas was used in testing; $\mathrm{M}$, mixed gas were used in testing; $\mathrm{H}$, humidified stream was used; $B$, Barrer; G, GPU. 


\section{Concluding Remarks}

The positive aspects of nanocomposite membranes for gas separation have prompted important and progressive interests in the development of this relatively new class of generation membranes. While nanocomposite membranes continue to be a dynamic and rapidly growing subject in gas separation, addressing their shortcomings remain a critical research topic. This review underlines the importance of nanofiller modifications as one of the promising tactics in designing defect-free high-performance $\mathrm{CO}_{2}$ separation nanocomposite membranes to fulfill the expectation of this new generation of membranes for practical application. Among the techniques employed for nanofiller modification, silanazation and amination are still the most common techniques by virtue of their simplicity, effectiveness and availability of wide range of modifying agents with multiple functionalities. Surface modification of nanofillers using dual-functional modifying agents such as amine-containing silane coupling and amine-containing ionic liquid is interesting as the modification can simultaneously improve the polymer-nanofiller compatibility and provide $\mathrm{CO}_{2}$-philic sites in a single step. As a conclusion, surface modification of nanofiller remains an attractive strategy to achieve multifunctionality to meet a broader range of characteristic and performance indicators. The development of new nanofiller modification approaches or optimization of the existing techniques and process provides a great prospect to enhance the membrane performances for the transition from bench to true industrial implementation.

Author Contributions: Conceptualization and writing-original draft, P.S.G.; writing-review and editing, K.C.W.; writing-review and editing, L.T.Y.; supervision, A.F.I.; writing-review and editing, M.S.A.; and writing-review and editing, B.C.N. All authors have read and agreed to the published version of the manuscript.

Funding: The authors would like to acknowledge the financial supports provided by "Universiti Teknologi Malaysia" under High Impact Research" (Vot No: 08G81).

Conflicts of Interest: The authors declare no conflict of interest.

$\begin{array}{ll}\text { Abbreviations } \\ \text { [APTMS][Ac] } & \begin{array}{l}\text { 3-(trimethoxysilyl) propan-1-aminium acetate } \\ \text { tetrafluoroborate }\end{array} \\ {[\mathrm{BF} 4]} & \text { 1-butyl-3-methylimidazolium } \\ {[\mathrm{Bmim}]} & \text { 1-ethyl-3-methylimidazolium } \\ \text { [Emim] } & \text { 1-hexyl-3-methylimidazolium } \\ {[\mathrm{Hmim}]} & \text { bis(trifluoromethylsulfonyl)imide } \\ \text { [Tf } \text { }_{2} \text { N } & \text { three-dimensional } \\ \text { 3D } & \text { 4,4'-(hexafluoroisopropylidene diphthalic anhydride) } \\ \text { 6FDA } & \text { N-(2-aminoethyl)-3-aminopropyl-trimethoxysilane } \\ \text { AAPTMS } & \text { N-[3-(dimethoxymethylsilyl)propyl ethylenediamine } \\ \text { AAPTMS } & \text { 3-(2-(2-aminoethylamino) ethylamino) propyltrimethoxysilane } \\ \text { AEPTMS } & \text { aminopropyl triethoxysilane } \\ \text { APTES } & \text { (3-aminopropyl)trimethoxysilane } \\ \text { APTMS } & \text { carbon nanotube } \\ \text { CNT } & \text { Copper-catalysed azide-alkyne cycloadditions } \\ \text { CuAAC } & \text { dopamine } \\ \text { DA } & \text { 2,4,6-trimethyl-m-phenylenediamine } \\ \text { DAM } & \text { deca-dodecasil 3 rhombohedral } \\ \text { DD3R } & \text { ethylenediamine } \\ \text { EDA } & \text { ethylene oxide } \\ \text { EO } & \text { graphene oxide } \\ \text { GO } & \text { 1H,1H,2H,2H-perflourodecyltriethoxysilane } \\ \text { HFDS } & \text { halloysite nanotube } \\ \text { HNT } & \text { ionic liquid } \\ \text { IL } & \text { layered double hydroxide } \\ \text { LDH } & \text { Linde Type A } \\ \text { LTA } & \end{array}$




$\begin{array}{ll}\text { MMM } & \text { mixed matrix membrane } \\ \text { MOF } & \text { metal organic framework } \\ \text { ODPA } & 4,4^{\prime} \text {-oxydiphthalicanhydride } \\ \text { PA } & \text { polyamide } \\ \text { PANI } & \text { polyanaline } \\ \text { PDA } & \text { polydopamine } \\ \text { PEBA } & \text { poly(ether-block-amide) } \\ \text { PEGDE } & \text { poly(ethylene glycol) diglycidyl ether } \\ \text { PEI } & \text { polyethyleneimine } \\ \text { PEO } & \text { poly(ethylene oxide) } \\ \text { PI } & \text { polyimide } \\ \text { PIM } & \text { polymers of intrinsic microporosity } \\ \text { PSf } & \text { polysulfone } \\ \text { PU } & \text { polyurethane } \\ \text { PVA } & \text { polyvinyl alcohol } \\ \text { PVAm } & \text { poly(vinylamine) } \\ \text { rGO } & \text { reduced graphene oxide } \\ \text { SAPO } & \text { silicoaluminophosphate } \\ \text { SPEEK } & \text { sulfonated poly(ether ether ketone) } \\ \text { ZIF } & \text { zeolitic imidazolate frameworks }\end{array}$

\section{References}

1. Bains, P.; Psarras, P.; Wilcox, J. $\mathrm{CO}_{2}$ capture from the industry sector. Prog. Energy Combust. Sci. 2017, 63, 146-172. [CrossRef]

2. Tay, W.H.; Lau, K.K.; Lai, L.S.; Shariff, A.M.; Wang, T. Current development and challenges in the intensified absorption technology for natural gas purification at offshore condition. J. Nat. Gas. Sci. Eng. 2019, 71, 102977. [CrossRef]

3. Wang, L.Y.; Xu, Y.L.; Li, Z.D.; Wei, Y.N.; Wei, J.P. $\mathrm{CO}_{2} / \mathrm{CH}_{4}$ and $\mathrm{H}_{2} \mathrm{~S} / \mathrm{CO}_{2}$ Selectivity by Ionic Liquids in Natural Gas Sweetening. Energy Fuels 2018, 32, 10-23. [CrossRef]

4. Rufford, T.E.; Smart, S.; Watson, G.C.Y.; Graham, B.F.; Boxall, J.; Da Costa, J.D.; May, E.F. The removal of $\mathrm{CO}_{2}$ and $\mathrm{N}_{2}$ from natural gas: A review of conventional and emerging process technologies. J. Pet. Sci. Eng. 2012, 94-95, 123-154. [CrossRef]

5. Chen, X.Y.; Vinh-Thang, H.; Ramirez, A.A.; Rodrigue, D.; Kaliaguine, S. Membrane gas separation technologies for biogas upgrading. RSC Adv. 2015, 5, 24399-24448. [CrossRef]

6. Adnan, A.I.; Ong, M.Y.; Nomanbhay, S.; Chew, K.W.; Show, P.L. Technologies for biogas upgrading to biomethane: A review. Bioengineering 2019, 6, 92. [CrossRef]

7. Tilahun, E.; Bayrakdar, A.; Sahinkaya, E.; Çalli, B. Performance of polydimethylsiloxane membrane contactor process for selective hydrogen sulfide removal from biogas. Waste Manag. 2017, 61, 250-257. [CrossRef]

8. Wang, Y.; Zhao, L.; Otto, A.; Robinius, M.; Stolten, D. A Review of Post-combustion $\mathrm{CO}_{2}$ Capture Technologies from Coal-fired Power Plants. Energy Procedia 2017, 114, 650-665. [CrossRef]

9. De Ras, K.; Van de Vijver, R.; Galvita, V.V.; Marin, G.B.; Van Geem, K.M. Carbon capture and utilization in the steel industry: Challenges and opportunities for chemical engineering. Curr. Opin. Chem. Eng. 2019, 26, 81-87. [CrossRef]

10. Ho, H.J.; Iizuka, A.; Shibata, E. Carbon Capture and Utilization Technology without Carbon Dioxide Purification and Pressurization: A Review on Its Necessity and Available Technologies. Ind. Eng. Chem. Res. 2019, 58, 8941-8954. [CrossRef]

11. Xu, G.; Liang, F.; Yang, Y.; Hu, Y.; Zhang, K.; Liu, W. An improved $\mathrm{CO}_{2}$ separation and purification system based on cryogenic separation and distillation theory. Energies 2014, 7, 3484-3502. [CrossRef]

12. Raza, A.; Gholami, R.; Rezaee, R.; Rasouli, V.; Rabiei, M. Significant aspects of carbon capture and storage-A review. Petroleum 2019, 5, 335-340. [CrossRef]

13. Nocito, F.; Dibenedetto, A. Atmospheric $\mathrm{CO}_{2}$ mitigation technologies: Carbon capture utilization and storage. Curr. Opin. Green Sustain. Chem. 2020, 21,34-43. [CrossRef] 
14. De Araújo, O.Q.F.; de Medeiros, J.L. Carbon capture and storage technologies: Present scenario and drivers of innovation. Curr. Opin. Chem. Eng. 2017, 17, 22-34. [CrossRef]

15. Maqsood, K.; Mullick, A.; Ali, A.; Kargupta, K.; Ganguly, S. Cryogenic carbon dioxide separation from natural gas: A review based on conventional and novel emerging technologies. Rev. Chem. Eng. 2014, 30, 453-477. [CrossRef]

16. Creamer, A.E.; Gao, B. Carbon-based adsorbents for postcombustion $\mathrm{CO}_{2}$ capture: A critical review. Environ. Sci. Technol. 2016, 50, 7276-7289. [CrossRef]

17. Zhu, X.; Li, S.; Shi, Y.; Cai, N. Recent advances in elevated-temperature pressure swing adsorption for carbon capture and hydrogen production. Prog. Energy Combust. Sci. 2019, 75, 100784. [CrossRef]

18. Liang, Z.H.; Rongwong, W.; Liu, H.; Fu, K.; Gao, H.; Cao, F.; Zhang, R.; Sema, T.; Henni, A.; Sumon, K.; et al. Recent progress and new developments in post-combustion carbon-capture technology with amine based solvents. Int. J. Greenh. Gas. Control. 2015, 40, 26-54. [CrossRef]

19. Dutcher, B.; Fan, M.; Russell, A.G. Amine-based $\mathrm{CO}_{2}$ capture technology development from the beginning of 2013-A review. ACS Appl. Mater. Interfaces 2015, 7, 2137-2148. [CrossRef]

20. Nematollahi, M.H.; Carvalho, P.J. Green solvents for $\mathrm{CO}_{2}$ capture. Curr. Opin. Green Sustain. Chem. 2019, 18, 25-30. [CrossRef]

21. Li, M.; Jiang, X.; He, G. Application of membrane separation technology in postcombustion carbon dioxide capture process. Front. Chem. Sci. Eng. 2014, 8, 233-239. [CrossRef]

22. Pohlmann, J.; Bram, M.; Wilkner, K.; Brinkmann, T. Pilot scale separation of $\mathrm{CO}_{2}$ from power plant flue gases by membrane technology. Int. J. Greenh. Gas Control 2016, 53, 56-64. [CrossRef]

23. Kárászová, M.; Zach, B.; Petrusová, Z.; Červenka, V.; Bobák, M.; Šyc, M.; Izák, P. Post-combustion carbon capture by membrane separation, Review. Sep. Purif. Technol. 2020, 238, 116448. [CrossRef]

24. Siagian, U.W.R.; Raksajati, A.; Himma, N.F.; Khoiruddin, K.; Wenten, I.G. Membrane-based carbon capture technologies: Membrane gas separation vs. membrane contactor. J. Nat. Gas. Sci. Eng. 2019, 67, 172-195. [CrossRef]

25. Sanders, D.F.; Smith, Z.P.; Guo, R.; Robeson, L.M.; McGrath, J.E.; Paul, D.R.; Freeman, B.D. Energy-efficient polymeric gas separation membranes for a sustainable future: A review. Polymer 2013, 54, 4729-4761. [CrossRef]

26. Han, Y.; Ho, W.S.W. Recent advances in polymeric membranes for $\mathrm{CO}_{2}$ capture. Chin. J. Chem. Eng. 2018, 26, 2238-2254. [CrossRef]

27. Kim, S.; Lee, Y.M. High performance polymer membranes for $\mathrm{CO}_{2}$ separation. Curr. Opin. Chem. Eng. 2013, 2, 238-244. [CrossRef]

28. Galizia, M.; Chi, W.S.; Smith, Z.P.; Merkel, T.C.; Baker, R.W.; Freeman, B.D. 50th Anniversary Perspective: Polymers and Mixed Matrix Membranes for Gas and Vapor Separation: A Review and Prospective Opportunities. Macromolecules 2017, 50, 7809-7843. [CrossRef]

29. Robeson, L.M. The upper bound revisited. J. Memb. Sci. 2008, 320, 390-400. [CrossRef]

30. Verweij, H. Inorganic membranes. Curr. Opin. Chem. Eng. 2012, 1, 156-162. [CrossRef]

31. Buonomenna, M.G. Design next generation membranes or rethink the "old" asymmetric membranes? Symmetry 2020, 12, 270. [CrossRef]

32. Shi, Y.; Liang, B.; Lin, R.B.; Zhang, C.; Chen, B. Gas Separation via Hybrid Metal-Organic Framework/Polymer Membranes. Trends Chem. 2020, 2, 254-269. [CrossRef]

33. Liang, C.Z.; Chung, T.S.; Lai, J.Y. A review of polymeric composite membranes for gas separation and energy production. Prog. Polym. Sci. 2019, 97, 101141. [CrossRef]

34. Wang, M.; Wang, Z.; Zhao, S.; Wang, J.; Wang, S. Recent advances on mixed matrix membranes for $\mathrm{CO}_{2}$ separation. Chin. J. Chem. Eng. 2017, 25, 1581-1597. [CrossRef]

35. Bastani, D.; Esmaeili, N.; Asadollahi, M. Polymeric mixed matrix membranes containing zeolites as a filler for gas separation applications: A review. J. Ind. Eng. Chem. 2013, 19, 375-393. [CrossRef]

36. Goh, P.S.; Ismail, A.F.; Sanip, S.M.; Ng, B.C.; Aziz, M. Recent advances of inorganic fillers in mixed matrix membrane for gas separation. Sep. Purif. Technol. 2011, 81, 243-264. [CrossRef]

37. Lu, P.; Liu, Y.; Zhou, T.; Wang, Q.; Li, Y. Recent advances in layered double hydroxides (LDHs) as two-dimensional membrane materials for gas and liquid separations. J. Memb. Sci. 2018, 567, 89-103. [CrossRef]

38. Rezakazemi, M.; Ebadi Amooghin, A.; Montazer-Rahmati, M.M.; Ismail, A.F.; Matsuura, T. State-of-the-art membrane based $\mathrm{CO}_{2}$ separation using mixed matrix membranes (MMMs): An overview on current status and future directions. Prog. Polym. Sci. 2014, 39, 817-861. [CrossRef] 
39. Vinoba, M.; Bhagiyalakshmi, M.; Alqaheem, Y.; Alomair, A.A.; Pérez, A.; Rana, M.S. Recent progress of fillers in mixed matrix membranes for $\mathrm{CO}_{2}$ separation: A review. Sep. Purif. Technol. 2017, 188, 431-450. [CrossRef]

40. Kalantari, S.; Omidkhah, M.; Ebadi Amooghin, A.; Matsuura, T. Superior interfacial design in ternary mixed matrix membranes to enhance the $\mathrm{CO}_{2}$ separation performance. Appl. Mater. Today 2020, 18, 100491. [CrossRef]

41. Wong, K.C.; Goh, P.S.; Ismail, A.F. Gas separation performance of thin film nanocomposite membranes incorporated with polymethyl methacrylate grafted multi-walled carbon nanotubes. Int. Biodeterior. Biodegrad. 2015, 102, 339-345. [CrossRef]

42. Liu, B.; Li, D.; Yao, J.; Sun, H. Improved $\mathrm{CO}_{2}$ separation performance and interfacial affinity of mixed matrix membrane by incorporating UiO-66-PEI@[bmim][Tf2N] particles. Sep. Purif. Technol. 2020, 239, 116519. [CrossRef]

43. Vu, M.T.; Lin, R.; Diao, H.; Zhu, Z.; Bhatia, S.K.; Smart, S. Effect of ionic liquids (ILs) on MOFs/polymer interfacial enhancement in mixed matrix membranes. J. Memb. Sci. 2019, 587, 117157. [CrossRef]

44. Meshkat, S.; Kaliaguine, S.; Rodrigue, D. Mixed matrix membranes based on amine and non-amine MIL-53(Al) in Pebax ${ }^{\circledR}$ MH-1657 for $\mathrm{CO}_{2}$ separation. Sep. Purif. Technol. 2018, 200, 177-190. [CrossRef]

45. Kargari, A.; Rezaeinia, S. State-of-the-art modification of polymeric membranes by PEO and PEG for carbon dioxide separation: A review of the current status and future perspectives. J. Ind. Eng. Chem. 2020, 84, 1-22. [CrossRef]

46. Ilyas, A.; Muhammad, N.; Gilani, M.A.; Vankelecom, I.F.J.; Khan, A.L. Effect of zeolite surface modification with ionic liquid [APTMS][Ac] on gas separation performance of mixed matrix membranes. Sep. Purif. Technol. 2018, 205, 176-183. [CrossRef]

47. Jomekian, A.; Bazooyar, B.; Behbahani, R.M.; Mohammadi, T.; Kargari, A. Ionic liquid-modified Pebax ${ }^{\circledR} 1657$ membrane filled by ZIF-8 particles for separation of $\mathrm{CO}_{2}$ from $\mathrm{CH}_{4}, \mathrm{~N}_{2}$ and $\mathrm{H}_{2}$. J. Memb. Sci. 2017, 524, 652-662. [CrossRef]

48. Pham, T.H.; Lee, B.K.; Kim, J. Novel improvement of $\mathrm{CO}_{2}$ adsorption capacity and selectivity by ethylenediamine-modified nano zeolite. J. Taiwan Inst. Chem. Eng. 2016, 66, 239-248. [CrossRef]

49. Wang, T.; Cheng, C.; Wu, L.G.; Shen, J.N.; Van der Bruggen, B.; Chen, Q.; Chen, D.; Dong, C.Y. Fabrication of Polyimide Membrane Incorporated with Functional Graphene Oxide for $\mathrm{CO}_{2}$ Separation: The Effects of GO Surface Modification on Membrane Performance. Environ. Sci. Technol. 2017, 51, 6202-6210. [CrossRef]

50. Huang, G.; Isfahani, A.P.; Muchtar, A.; Sakurai, K.; Shrestha, B.B.; Qin, D.; Yamaguchi, D.; Sivaniah, E.; Ghalei, B. Pebax/ionic liquid modified graphene oxide mixed matrix membranes for enhanced $\mathrm{CO}_{2}$ capture. J. Memb. Sci. 2018, 565, 370-379. [CrossRef]

51. Habibiannejad, S.A.; Aroujalian, A.; Raisi, A. Pebax-1657 mixed matrix membrane containing surface modified multi-walled carbon nanotubes for gas separation. RSC Adv. 2016, 6, 79563-79577. [CrossRef]

52. Ma, L.; Svec, F.; Lv, Y.; Tan, T. Engineering of the Filler/Polymer Interface in Metal-Organic Framework-Based Mixed-Matrix Membranes to Enhance Gas Separation. Chem. Asian J. 2019, 14, 3502-3514. [CrossRef] [PubMed]

53. Ebadi Amooghin, A.; Mashhadikhan, S.; Sanaeepur, H.; Moghadassi, A.; Matsuura, T.; Ramakrishna, S. Substantial breakthroughs on function-led design of advanced materials used in mixed matrix membranes (MMMs): A new horizon for efficient $\mathrm{CO}_{2}$ separation. Prog. Mater. Sci. 2019, 102, 222-295. [CrossRef]

54. Lee, J.S.; Heo, S.A.; Jo, H.J.; Min, B.R. Preparation and characteristics of cross-linked cellulose acetate ultrafiltration membranes with high chemical resistance and mechanical strength. React. Funct. Polym. 2016, 99, 114-121. [CrossRef]

55. Song, X.; Zhou, Q.; Zhang, T.; Xu, H.; Wang, Z. Pressure-assisted preparation of graphene oxide quantum dot-incorporated reverse osmosis membranes: Antifouling and chlorine resistance potentials. J. Mater. Chem. A 2016, 4, 16896-16905. [CrossRef]

56. Verbeke, R.; Gómez, V.; Vankelecom, I.F.J. Chlorine-resistance of reverse osmosis (RO) polyamide membranes. Prog. Polym. Sci. 2017, 72,1-15. [CrossRef]

57. Swaidan, R.; Ghanem, B.; Litwiller, E.; Pinnau, I. Physical Aging, Plasticization and Their Effects on Gas Permeation in "rigid" Polymers of Intrinsic Microporosity. Macromolecules 2015, 48, 6553-6561. [CrossRef]

58. Xia, J.; Chung, T.S.; Paul, D.R. Physical aging and carbon dioxide plasticization of thin polyimide films in mixed gas permeation. J. Memb. Sci. 2014, 450, 457-468. [CrossRef]

59. Wang, T.; Zhao, L.; Shen, J.N.; Wu, L.G.; Van Der Bruggen, B. Enhanced Performance of Polyurethane Hybrid Membranes for $\mathrm{CO}_{2}$ Separation by Incorporating Graphene Oxide: The Relationship between Membrane Performance and Morphology of Graphene Oxide. Environ. Sci. Technol. 2015, 49, 8004-8011. [CrossRef] 
60. Rudra, R.; Kumar, V.; Kundu, P.P. Acid catalysed cross-linking of poly vinyl alcohol (PVA) by glutaraldehyde: Effect of crosslink density on the characteristics of PVA membranes used in single chambered microbial fuel cells. RSC Adv. 2015, 5, 83436-83447. [CrossRef]

61. Kausar, A. Investigation on Nanocomposite Membrane of Multiwalled Carbon Nanotube Reinforced Polycarbonate Blend for Gas Separation. J. Nanomater. 2016, 2016, 1-9. [CrossRef]

62. Zuo, J.; Wang, Y.; Chung, T.S. Novel organic-inorganic thin film composite membranes with separation performance surpassing ceramic membranes for isopropanol dehydration. J. Memb. Sci. 2013, 433, 60-71. [CrossRef]

63. Dong, G.; Zhang, X.; Zhang, Y.; Tsuru, T. Enhanced permeation through $\mathrm{CO}_{2}$-stable dual-inorganic composite membranes with tunable nanoarchitectured channels. ACS Sustain. Chem. Eng. 2018, 6, 8515-8524. [CrossRef]

64. Zhang, Y.; Tan, X.; Xie, Q.; Chen, J.; Ding, X.; Hua, M.; Zhao, H. High performance post-modified polymers of intrinsic microporosity (PIM-1) membranes based on multivalent metal ions for gas separation. J. Memb. Sci. 2016, 514, 305-312.

65. Shaulsky, E.; Nejati, S.; Boo, C.; Perreault, F.; Osuji, C.O.; Elimelech, M. Post-fabrication modification of electrospun nanofiber mats with polymer coating for membrane distillation applications. J. Memb. Sci. 2017, 530, 158-165. [CrossRef]

66. Asghar, H.; Ilyas, A.; Tahir, Z.; Li, X.; Khan, A.L. Fluorinated and sulfonated poly (ether ether ketone) and Matrimid blend membranes for $\mathrm{CO}_{2}$ separation. Sep. Purif. Technol. 2018, 203, 233-241. [CrossRef]

67. Qiu, W.; Xu, L.; Chen, C.C.; Paul, D.R.; Koros, W.J. Gas separation performance of 6FDA-based polyimides with different chemical structures. Polymer 2013, 54, 6226-6235. [CrossRef]

68. Favvas, E.P.; Katsaros, F.K.; Papageorgiou, S.K.; Sapalidis, A.A.; Mitropoulos, A.C. A review of the latest development of polyimide based membranes for $\mathrm{CO}_{2}$ separations. React. Funct. Polym. 2017, 120, 104-130. [CrossRef]

69. Wang, Z.; Wang, D.; Zhang, F.; Jin, J. Tröger's Base-Based Microporous Polyimide Membranes for High-Performance Gas Separation. ACS Macro Lett. 2014, 3, 597-601. [CrossRef]

70. Wang, Y.; Ma, X.; Ghanem, B.S.; Alghunaimi, F.; Pinnau, I.; Han, Y. Polymers of intrinsic microporosity for energy-intensive membrane-based gas separations. Mater. Today Nano 2018, 3, 69-95. [CrossRef]

71. Lau, C.H.; Li, P.; Li, F.; Chung, T.; Paul, D.R. Reverse-selective polymeric membranes for gas separations. Prog. Polym. Sci. 2013, 38, 740-766. [CrossRef]

72. Bernardo, P.; Bazzarelli, F.; Tasselli, F.; Clarizia, G.; Mason, C.R.; Maynard-Atem, L.; Budd, P.M.; Lanč, M.; Pilnáček, K.; Vopička, O.; et al. Effect of physical aging on the gas transport and sorption in PIM-1 membranes. Polymer 2017, 113, 283-294. [CrossRef]

73. Usman, M.; Ahmed, A.; Yu, B.; Peng, Q.; Shen, Y.; Cong, H. Corrigendum to “A review of different synthetic approaches of amorphous intrinsic microporous polymers and their potential applications in membrane-based gases separation". Eur. Polym. J. 2019, 121, 109322. [CrossRef]

74. Sanders, D.F.; Smith, Z.P.; Ribeiro, C.P.; Guo, R.; McGrath, J.E.; Paul, D.R.; Freeman, B.D. Gas permeability, diffusivity, and free volume of thermally rearranged polymers based on 3,3'-dihydroxy-4, $4^{\prime}$-diamino-biphenyl (HAB) and 2,2'-bis-(3,4-dicarboxyphenyl) hexafluoropropane dianhydride (6FDA). J. Memb. Sci. 2012, 409-410, 232-241. [CrossRef]

75. Jiang, X.; Li, S.; Shao, L. Pushing $\mathrm{CO}_{2}$-philic membrane performance to the limit by designing semi-interpenetrating networks (SIPN) for sustainable $\mathrm{CO}_{2}$ separations. Energy Environ. Sci. 2017, 10, 1339-1344. [CrossRef]

76. Bandehali, S.; Moghadassi, A.; Parvizian, F.; Hosseini, S.M.; Matsuura, T.; Joudaki, E. Advances in high carbon dioxide separation performance of poly (ethylene oxide)-based membranes. J. Energy Chem. 2020, 46, 30-52. [CrossRef]

77. Rea, R.; De Angelis, M.G.; Baschetti, M.G. Models for facilitated transport membranes: A review. Membranes 2019, 9, 26. [CrossRef]

78. Kim, T.J.; Vrålstad, H.; Sandru, M.; Hägg, M.B. Separation performance of PVAm composite membrane for $\mathrm{CO}_{2}$ capture at various $\mathrm{pH}$ levels. J. Memb. Sci. 2013, 428, 218-224. [CrossRef]

79. Shi, M.; Dong, C.; Wang, Z.; Tian, X.; Zhao, S.; Wang, J. Support surface pore structures matter: Effects of support surface pore structures on the TFC gas separation membrane performance over a wide pressure range. Chin. J. Chem. Eng. 2019, 27, 1807-1816. [CrossRef]

80. Vakharia, V.; Salim, W.; Wu, D.; Han, Y.; Chen, Y.; Zhao, L.; Ho, W.S.W. Scale-up of amine-containing thin-film composite membranes for $\mathrm{CO}_{2}$ capture from flue gas. J. Memb. Sci. 2018, 555, 379-387. [CrossRef]

81. Deng, L.; Hägg, M. Carbon nanotube reinforced PVAm/PVA blend FSC nanocomposite membrane for $\mathrm{CO}_{2} / \mathrm{CH}_{4}$ separation. Int. J. Greenh. Gas Control 2014, 26, 127-134. [CrossRef] 
82. Liu, J.; Bae, T.H.; Qiu, W.; Husain, S.; Nair, S.; Jones, C.W.; Chance, R.R.; Koros, W.J. Butane isomer transport properties of 6FDA-DAM and MFI-6FDA-DAM mixed matrix membranes. J. Memb. Sci. 2009, 343, 157-163. [CrossRef]

83. Duval, J.M.; Folkers, B.; Mulder, M.H.V.; Desgrandchamps, G.; Smolders, C.A. Adsorbent filled membranes for gas separation. Part 1. Improvement of the gas separation properties of polymeric membranes by incorporation of microporous adsorbents. J. Memb. Sci. 1993, 80, 189-198. [CrossRef]

84. Vu, D.Q.; Koros, W.J.; Miller, S.J. Mixed matrix membranes using carbon molecular sieves. J. Memb. Sci. 2003, 211, 335-348. [CrossRef]

85. Čejka, J.; Millini, R.; Opanasenko, M.; Serrano, D.P.; Roth, W.J. Advances and challenges in zeolite synthesis and catalysis. Catal. Today 2019, 345, 2-13. [CrossRef]

86. Collins, F.; Rozhkovskaya, A.; Outram, J.G.; Millar, G.J. A critical review of waste resources, synthesis, and applications for Zeolite LTA. Microporous Mesoporous Mater. 2020, 291, 109667. [CrossRef]

87. Zhou, R.; Ping, E.W.; Funke, H.H.; Falconer, J.L.; Noble, R.D. Improving SAPO-34 membrane synthesis. J. Memb. Sci. 2013, 444, 384-393. [CrossRef]

88. Cheung, O.; Hedin, N. Zeolites and related sorbents with narrow pores for $\mathrm{CO}_{2}$ separation from flue gas. RSC Adv. 2014, 4, 14480-14494. [CrossRef]

89. Cui, Y.; Kita, H.; Okamoto, K.-I. Preparation and gas separation properties of zeolite T membrane. Chem. Commun. 2003, 9, 2154-2155. [CrossRef]

90. Chen, X.Y.; Nik, O.G.; Rodrigue, D.; Kaliaguine, S. Mixed matrix membranes of aminosilanes grafted FAU/EMT zeolite and cross-linked polyimide for $\mathrm{CO}_{2} / \mathrm{CH}_{4}$ separation. Polymer 2012, 53, 3269-3280. [CrossRef]

91. Bradshaw, D.; Garai, A.; Huo, J. Metal-organic framework growth at functional interfaces: Thin films and composites for diverse applications. Chem. Soc. Rev. 2012, 41, 2344-2381. [CrossRef]

92. Bai, Y.; Dou, Y.; Xie, L.H.; Rutledge, W.; Li, J.R.; Zhou, H.C. Zr-based metal-organic frameworks: Design, synthesis, structure, and applications. Chem. Soc. Rev. 2016, 45, 2327-2367. [CrossRef] [PubMed]

93. Venna, S.R.; Jasinski, J.B.; Carreon, M.A. Structural Evolution of Zeolitic Imidazolate Framework-8. J. Am. Chem. Soc. 2010, 132, 18030-18033. [CrossRef] [PubMed]

94. Feng, S.; Bu, M.; Pang, J.; Fan, W.; Fan, L.; Zhao, H.; Yang, G.; Guo, H.; Kong, G.; Sun, H.; et al. Hydrothermal stable ZIF-67 nanosheets via morphology regulation strategy to construct mixed-matrix membrane for gas separation. J. Membr. Sci. 2020, 593, 117404. [CrossRef]

95. Ban, Y.; Li, Y.; Liu, X.; Peng, Y.; Yang, W. Solvothermal synthesis of mixed-ligand metal-organic framework ZIF-78 with controllable size and morphology. Microporous Mesoporous Mater. 2013, 173, 29-36. [CrossRef]

96. Bae, T.H.; Lee, J.S.; Qiu, W.; Koros, W.J.; Jones, C.W.; Nair, S. A high-performance gas-separation membrane containing submicrometer-sized metal-organic framework crystals. Angew. Chem. Int. Ed. 2010, 49, 9863-9866. [CrossRef]

97. Nguyen, N.T.T.; Furukawa, H.; Gándara, F.; Nguyen, H.T.; Cordova, K.E.; Yaghi, O.M. Selective capture of carbon dioxide under humid conditions by hydrophobic chabazite-type zeolitic imidazolate frameworks. Angew. Chem. Int. Ed. 2014, 53, 10645-10648. [CrossRef]

98. Abednatanzi, S.; Abbasi, A.; Masteri-Farahani, M. Post-synthetic modification of nanoporous $\mathrm{Cu}_{3}(\mathrm{BTC})_{2}$ metal-organic framework via immobilization of a molybdenum complex for selective epoxidation. J. Mol. Catal. A Chem. 2015, 399, 10-17. [CrossRef]

99. Ghanbari, T.; Abnisa, F.; Wan Daud, W.M.A. A review on production of metal organic frameworks (MOF) for $\mathrm{CO}_{2}$ adsorption. Sci. Total Env. 2020, 707, 135090. [CrossRef] [PubMed]

100. Zhu, H.; Wang, L.; Jie, X.; Liu, D.; Cao, Y. Improved Interfacial Affinity and $\mathrm{CO}_{2}$ Separation Performance of Asymmetric Mixed Matrix Membranes by Incorporating Postmodified MIL-53(Al). ACS Appl. Mater. Interfaces 2016, 8, 22696-22704. [CrossRef] [PubMed]

101. Kazemi, S.; Safarifard, V. Carbon dioxide capture in MOFs: The effect of ligand functionalization. Polyhedron 2018, 154, 236-251. [CrossRef]

102. Sabetghadam, A.; Seoane, B.; Keskin, D.; Duim, N.; Rodenas, T.; Shahid, S.; Sorribas, S.; Le Guillouzer, C.; Clet, G.; Tellez, C.; et al. Metal Organic Framework Crystals in Mixed-Matrix Membranes: Impact of the Filler Morphology on the Gas Separation Performance. Adv. Funct. Mater. 2016, 26, 3154-3163. [CrossRef] [PubMed]

103. Lin, Y.; Kong, C.; Zhang, Q.; Chen, L. Metal-Organic Frameworks for Carbon Dioxide Capture and Methane Storage. Adv. Energy Mater. 2017, 7, 1601296. [CrossRef] 
104. Calvaresi, M.; Zerbetto, F. Atomistic molecular dynamics simulations reveal insights into adsorption, packing, and fluxes of molecules with carbon nanotubes. J. Mater. Chem. A 2014, 2, 12123-12135. [CrossRef]

105. Liu, L.; Nicholson, D.; Bhatia, S.K. Exceptionally high performance of charged carbon nanotube arrays for $\mathrm{CO}_{2}$ separation from flue gas. Carbon 2017, 125, 245-257. [CrossRef]

106. Wong, K.C.; Goh, P.S.; Ng, B.C.; Ismail, A.F. Thin film nanocomposite embedded with polymethyl methacrylate modified multi-walled carbon nanotubes for $\mathrm{CO}_{2}$ removal. RSC Adv. 2015, 5, 31683-31690. [CrossRef]

107. Goh, P.S.; Ng, B.C.; Ismail, A.F.; Aziz, M.; Hayashi, Y. Pre-treatment of multi-walled carbon nanotubes for polyetherimide mixed matrix hollow fiber membranes. J. Colloid Interface Sci. 2012, 386, 80-87. [CrossRef]

108. Goh, P.S.; Ng, B.C.; Ismail, A.F.; Sanip, S.M.; Aziz, M.; Kassim, M.A. Effect of dispersed multi-walled carbon nanotubes on mixed matrix membrane for $\mathrm{O}_{2} / \mathrm{N}_{2}$ separation. Sep. Sci. Technol. 2011, 46, 1250-1261. [CrossRef]

109. Chi, C.; Wang, X.; Peng, Y.; Qian, Y.; Hu, Z.; Dong, J.; Zhao, D. Facile Preparation of Graphene Oxide Membranes for Gas Separation. Chem. Mater. 2016, 28, 2921-2927. [CrossRef]

110. Zahri, K.; Goh, P.S.; Ismail, A.F. The incorporation of graphene oxide into polysulfone mixed matrix membrane for $\mathrm{CO}_{2} / \mathrm{CH}_{4}$ separation. In Proceedings of the IOP Conference Series: Earth and Environmental Science, Kota Kinabalu, Malaysia, 9-12 December 2015; Volume 36, p. 012007.

111. Darensbourg, D.J.; Kudaroski, R.A. The Activation of Carbon Dioxide by Metai Complexes. Adv. Organomet. Chem. 1983, 22, 129-168.

112. Jang, D.I.; Park, S.J. Influence of nickel oxide on carbon dioxide adsorption behaviors of activated carbons. Fuel 2012, 102, 439-444. [CrossRef]

113. Tang, Q.L.; Luo, Q.H. Adsorption of $\mathrm{CO}_{2}$ at $\mathrm{ZnO}$ : A surface structure effect from DFT+ U Calculations. J. Phys. Chem. C 2013, 117, 22954-22966. [CrossRef]

114. Yoon, K.W.; Kim, H.; Kang, Y.S.; Kang, S.W. 1-Butyl-3-methylimidazolium tetrafluoroborate/zinc oxide composite membrane for high $\mathrm{CO}_{2}$ separation performance. Chem. Eng. J. 2017, 320, 50-54. [CrossRef]

115. Ahmadizadegan, H. Synthesis and gas transport properties of novel functional polyimide/ZnO nanocomposite thin film membranes. RSC Adv. 2016, 6, 106778-106789. [CrossRef]

116. Yong, Z.; Mata, V.; Rodrigues, A.E. Adsorption of carbon dioxide onto hydrotalcite-like compounds (HTlcs) at high temperatures. Ind. Eng. Chem. Res. 2001, 40, 204-209. [CrossRef]

117. Xie, K.; Fu, Q.; Qiao, G.G.; Webley, P.A. Recent progress on fabrication methods of polymeric thin film gas separation membranes for $\mathrm{CO}_{2}$ capture. J. Memb. Sci. 2019, 572, 38-60. [CrossRef]

118. Yuan, F.; Wang, Z.; Li, S.; Wang, J.; Wang, S. Formation-structure-performance correlation of thin film composite membranes prepared by interfacial polymerization for gas separation. J. Memb. Sci. 2012, 421-422, 327-341. [CrossRef]

119. Aroon, M.A.; Ismail, A.F.; Matsuura, T.; Montazer-Rahmati, M.M. Performance studies of mixed matrix membranes for gas separation: A review. Sep. Purif. Technol. 2010, 75, 229-242. [CrossRef]

120. Wang, M.; Wang, Z.; Li, N.; Liao, J.; Zhao, S.; Wang, J.; Wang, S. Relationship between polymer-filler interfaces in separation layers and gas transport properties of mixed matrix composite membranes. J. Memb. Sci. 2015, 495, 252-268. [CrossRef]

121. Zhang, J.; Xin, Q.; Li, X.; Yun, M.; Xu, R.; Wang, S.; Li, Y.; Lin, L.; Ding, X.; Ye, H.; et al. Mixed matrix membranes comprising aminosilane-functionalized graphene oxide for enhanced $\mathrm{CO}_{2}$ separation. J. Memb. Sci. 2019, 570-571, 343-354. [CrossRef]

122. Wong, K.C.; Goh, P.S.; Ismail, A.F. Thin film nanocomposite: The next generation selective membrane for $\mathrm{CO}_{2}$ removal. J. Mater. Chem. A 2016, 4, 15726-15748. [CrossRef]

123. Sabetghadam, A.; Liu, X.; Orsi, A.F.; Lozinska, M.M.; Johnson, T.; Jansen, K.M.B.; Wright, P.A.; Carta, M.; McKeown, N.B.; Kapteijn, F.; et al. Towards High Performance Metal-Organic Framework-Microporous Polymer Mixed Matrix Membranes: Addressing Compatibility and Limiting Aging by Polymer Doping. Chem. Eur. J. 2018, 24, 12796-12800. [CrossRef] [PubMed]

124. Shen, J.; Liu, G.; Huang, K.; Jin, W.; Lee, K.R.; Xu, N. Membranes with fast and selective gas-transport channels of laminar graphene oxide for efficient $\mathrm{CO}_{2}$ capture. Angew. Chem. Int. Ed. 2015, 54, 578-582.

125. Castro-Muñoz, R.; Fíla, V. Effect of the ZIF-8 Distribution in Mixed-Matrix Membranes Based on Matrimid ${ }^{\circledR}$ 5218-PEG on $\mathrm{CO}_{2}$ Separation. Chem. Eng. Technol. 2019, 42, 744-752. [CrossRef] 
126. Venna, S.R.; Lartey, M.; Li, T.; Spore, A.; Kumar, S.; Nulwala, H.B.; Luebke, D.R.; Rosi, N.L.; Albenze, E. Fabrication of MMMs with improved gas separation properties using externally-functionalized MOF particles. J. Mater. Chem. A 2015, 3, 5014-5022. [CrossRef]

127. Mubashir, M.; Yeong, Y.F.; Chew, T.L.; Lau, K.K. Optimization of spinning parameters on the fabrication of $\mathrm{NH}_{2}$-MIL-53(Al)/cellulose acetate (CA) hollow fiber mixed matrix membrane for $\mathrm{CO}_{2}$ separation. Sep. Purif. Technol. 2019, 215, 32-43. [CrossRef]

128. Marti, A.M.; Venna, S.R.; Roth, E.A.; Culp, J.T.; Hopkinson, D.P. Simple Fabrication Method for Mixed Matrix Membranes with in Situ MOF Growth for Gas Separation. ACS Appl. Mater. Interfaces 2018, 10, 24784-24790. [CrossRef]

129. Thompson, J.A.; Chapman, K.W.; Koros, W.J.; Jones, C.W.; Nair, S. Sonication-induced Ostwald ripening of ZIF-8 nanoparticles and formation of ZIF-8/polymer composite membranes. Microporous Mesoporous Mater. 2012, 158, 292-299. [CrossRef]

130. Jia, M.; Zhang, X.F.; Feng, Y.; Zhou, Y.; Yao, J. In-situ growing ZIF-8 on cellulose nanofibers to form gas separation membrane for $\mathrm{CO}_{2}$ separation. J. Memb. Sci. 2020, 595, 2-7. [CrossRef]

131. Chen, X.Y.; Razzaz, Z.; Kaliaguine, S.; Rodrigue, D. Mixed matrix membranes based on silica nanoparticles and microcellular polymers for $\mathrm{CO}_{2} / \mathrm{CH}_{4}$ separation. J. Cell. Plast. 2018, 54, 309-331. [CrossRef]

132. Al-Maythalony, B.A.; Alloush, A.M.; Faizan, M.; Dafallah, H.; Elgzoly, M.A.A.; Seliman, A.A.A.; Al-Ahmed, A.; Yamani, Z.H.; Habib, M.A.M.; Cordova, K.E.; et al. Tuning the interplay between selectivity and permeability of ZIF-7 mixed matrix membranes. ACS Appl. Mater. Interfaces 2017, 9, 33401-33407. [CrossRef] [PubMed]

133. Shen, X.; Du, H.; Mullins, R.H.; Kommalapati, R.R. Polyethylenimine Applications in Carbon Dioxide Capture and Separation: From Theoretical Study to Experimental Work. Energy Technol. 2017, 5, 822-833. [CrossRef]

134. Shishatskiy, S.; Pauls, J.R.; Nunes, S.P.; Peinemann, K.V. Quaternary ammonium membrane materials for $\mathrm{CO}_{2}$ separation. J. Memb. Sci. 2010, 359, 44-53. [CrossRef]

135. Isanejad, M.; Mohammadi, T. Effect of amine modification on morphology and performance of poly (ether-block-amide)/fumed silica nanocomposite membranes for $\mathrm{CO}_{2} / \mathrm{CH}_{4}$ separation. Mater. Chem. Phys. 2018, 205, 303-314. [CrossRef]

136. Ghanem, M.A.; Kocak, I.; Al-Mayouf, A.; Alhoshan, M.; Bartlett, P.N. Covalent modification of carbon nanotubes with anthraquinone by electrochemical grafting and solid phase synthesis. Electrochim. Acta 2012, 68, 74-80. [CrossRef]

137. Ata, M.S.; Poon, R.; Syed, A.M.; Milne, J.; Zhitomirsky, I. New developments in non-covalent surface modification, dispersion and electrophoretic deposition of carbon nanotubes. Carbon 2018, 130, 584-598. [CrossRef]

138. Purkait, T.K.; Iqbal, M.; Islam, M.A.; Mobarok, M.H.; Gonzalez, C.M.; Hadidi, L.; Veinot, J.G.C. Alkoxy-Terminated Si Surfaces: A New Reactive Platform for the Functionalization and Derivatization of Silicon Quantum Dots. J. Am. Chem. Soc. 2016, 138, 7114-7120. [CrossRef]

139. Ambrogi, V.; Carfagna, C.; Cerruti, P.; Marturano, V. Additives in Polymers. In Modification of Polymer Properties; Elsevier: Amsterdam, The Netherlands, 2017; pp. 87-108.

140. Rosyadah Ahmad, N.N.; Mukhtar, H.; Mohshim, D.F.; Nasir, R.; Man, Z. Surface modification in inorganic filler of mixed matrix membrane for enhancing the gas separation performance. Rev. Chem. Eng. 2016, 32, 181-200.

141. Laghaei, M.; Sadeghi, M.; Ghalei, B.; Shahrooz, M. The role of compatibility between polymeric matrix and silane coupling agents on the performance of mixed matrix membranes: Polyethersulfone/MCM-41. J. Memb. Sci. 2016, 513, 20-32. [CrossRef]

142. Ebadi Amooghin, A.; Omidkhah, M.; Kargari, A. The effects of aminosilane grafting on NaY zeolite-Matrimid ${ }^{\circledR} 5218$ mixed matrix membranes for $\mathrm{CO}_{2} / \mathrm{CH}_{4}$ separation. J. Memb. Sci. 2015, 490, 364-379. [CrossRef]

143. Junaidi, M.U.M.; Khoo, C.P.; Leo, C.P.; Ahmad, A.L. The effects of solvents on the modification of SAPO-34 zeolite using 3-aminopropyl trimethoxy silane for the preparation of asymmetric polysulfone mixed matrix membrane in the application of $\mathrm{CO}_{2}$ separation. Microporous Mesoporous Mater. 2014, 192, 52-59. [CrossRef]

144. Jusoh, N.; Yeong, Y.F.; Lau, K.K.M.; Shariff, A. Fabrication of silanated zeolite T/6FDA-durene composite membranes for $\mathrm{CO}_{2} / \mathrm{CH}_{4}$ separation. J. Clean. Prod. 2017, 166, 1043-1058. [CrossRef]

145. Asgari, M.; Sundararaj, U. Silane functionalization of sodium montmorillonite nanoclay: The effect of dispersing media on intercalation and chemical grafting. Appl. Clay Sci. 2018, 153, 228-238. [CrossRef] 
146. Junaidi, M.U.M.; Leo, C.P.; Ahmad, A.L.; Ahmad, N.A. Fluorocarbon functionalized SAPO-34 zeolite incorporated in asymmetric mixed matrix membranes for carbon dioxide separation in wet gases. Microporous Mesoporous Mater. 2015, 206, 23-33. [CrossRef]

147. Ghalei, B.; Sakurai, K.; Kinoshita, Y.; Wakimoto, K.; Isfahani, A.P.; Song, Q.; Doitomi, K.; Furukawa, S.; Hirao, H.; Kusuda, H.; et al. Enhanced selectivity in mixed matrix membranes for $\mathrm{CO}_{2}$ capture through efficient dispersion of amine-functionalized MOF nanoparticles. Nat. Energy 2017, 2, 17086. [CrossRef]

148. Jia, M.; Feng, Y.; Qiu, J.; Zhang, X.F.; Yao, J. Amine-functionalized MOFs@GO as filler in mixed matrix membrane for selective $\mathrm{CO}_{2}$ separation. Sep. Purif. Technol. 2019, 213, 63-69. [CrossRef]

149. Atash Jameh, A.; Mohammadi, T.; Bakhtiari, O. Preparation of PEBAX-1074/modified ZIF-8 nanoparticles mixed matrix membranes for $\mathrm{CO}_{2}$ removal from natural gas. Sep. Purif. Technol. 2020, 231, 115900. [CrossRef]

150. Noroozi, Z.; Bakhtiari, O. Preparation of amino functionalized titanium oxide nanotubes and their incorporation within Pebax/PEG blended matrix for $\mathrm{CO}_{2} / \mathrm{CH}_{4}$ separation. Chem. Eng. Res. Des. 2019, 152, 149-164. [CrossRef]

151. Vaesen, S.; Guillerm, V.; Yang, Q.; Wiersum, A.D.; Marszalek, B.; Gil, B.; Vimont, A.; Daturi, M.; Devic, T.; Llewellyn, P.L.; et al. A robust amino-functionalized titanium (IV) based MOF for improved separation of acid gases. Chem. Commun. 2013, 49, 10082. [CrossRef]

152. Waqas Anjum, M.; Bueken, B.; De Vos, D.; Vankelecom, I.F.J. MIL-125(Ti) based mixed matrix membranes for $\mathrm{CO}_{2}$ separation from $\mathrm{CH}_{4}$ and $\mathrm{N}_{2}$. J. Memb. Sci. 2016, 502, 21-28. [CrossRef]

153. Kim, H.-J.; Yang, H.-C.; Chung, D.-Y.; Yang, I.-H.; Choi, Y.J.; Moon, J. Functionalized Mesoporous Silica Membranes for $\mathrm{CO}_{2}$ Separation Applications. J. Chem. 2015, 2015, 1-9.

154. Ansaloni, L.; Zhao, Y.; Jung, B.T.; Ramasubramanian, K.; Baschetti, M.G.; Ho, W.S.W. Facilitated transport membranes containing amino-functionalized multi-walled carbon nanotubes for high-pressure $\mathrm{CO}_{2}$ separations. J. Memb. Sci. 2015, 490, 18-28. [CrossRef]

155. Chen, B.; Jin, Z.; Pei, X.; Li, J.; Liu, C.; Zhao, H. Liquid-like secondary amine containing POSS as reactive nanoadditive to improve the anticorrosion performance of epoxy coating. Mater. Lett. 2020, 261, 127103. [CrossRef]

156. Shao, W.; Liu, C.; Ma, H.; Hong, Z.; Xie, Q.; Lu, Y. Fabrication of pH-sensitive thin-film nanocomposite nanofiltration membranes with enhanced performance by incorporating amine-functionalized graphene oxide. Appl. Surf. Sci. 2019, 487, 1209-1221. [CrossRef]

157. Heo, J.H.; Lee, J.W.; Lee, B.; Cho, H.H.; Lim, B.; Lee, J.H. Chemical effects of organo-silanized $\mathrm{SiO}_{2}$ nanofillers on epoxy adhesives. J. Ind. Eng. Chem. 2017, 54, 184-189. [CrossRef]

158. Wang, Y.; Zhang, X.; Li, J.; Liu, C.; Gao, Y.; Li, N.; Xie, Z. Enhancing the $\mathrm{CO}_{2}$ separation performance of SPEEK membranes by incorporation of polyaniline-decorated halloysite nanotubes. J. Memb. Sci. 2019, 573, 602-611. [CrossRef]

159. Suhaimi, N.H.; Yeong, Y.F.; Ch'ng, C.W.M.; Jusoh, N. Tailoring $\mathrm{CO}_{2} / \mathrm{CH}_{4}$ Separation Performance of Mixed Matrix Membranes by Using ZIF-8 Particles Functionalized with Different Amine Groups. Polymer 2019, 11, 2042. [CrossRef]

160. Zhu, H.; Yuan, J.; Zhao, J.; Liu, G.; Jin, W. Enhanced $\mathrm{CO}_{2} / \mathrm{N}_{2}$ separation performance by using dopamine/ polyethyleneimine-grafted $\mathrm{TiO}_{2}$ nanoparticles filled PEBA mixed-matrix membranes. Sep. Purif. Technol. 2019, 214, 78-86. [CrossRef]

161. Xin, Q.; Li, Z.; Li, C.; Wang, S.; Jiang, Z.; Wu, H.; Zhang, Y.; Yang, J.; Cao, X. Enhancing the $\mathrm{CO}_{2}$ separation performance of composite membranes by the incorporation of amino acid-functionalized graphene oxide. J. Mater. Chem. A 2015, 3, 6629-6641. [CrossRef]

162. Ge, B.S.; Wang, T.; Sun, H.X.; Gao, W.; Zhao, H.R. Preparation of mixed matrix membranes based on polyimide and aminated graphene oxide for $\mathrm{CO}_{2}$ separation. Polym. Adv. Technol. 2018, 29, 1334-1343. [CrossRef]

163. Mohammed, S.A.; Nasir, A.M.; Aziz, F.; Kumar, G.; Sallehhudin, W.; Jaafar, J.; Lau, W.J.; Yusof, N.; Salleh, W.N.W.; Ismail, A.F. $\mathrm{CO}_{2} / \mathrm{N}_{2}$ selectivity enhancement of PEBAX MH 1657/Aminated partially reduced graphene oxide mixed matrix composite membrane. Sep. Purif. Technol. 2019, 223, 142-153. [CrossRef]

164. Raimondo, M.; Naddeo, C.; Vertuccio, L.; Bonnaud, L.; Dubois, P.; Binder, W.H.; Sorrentino, A.; Guadagno, L. Multifunctionality of structural nanohybrids: The crucial role of carbon nanotube covalent and non-covalent functionalization in enabling high thermal, mechanical and self-healing performance. Nanotechnology 2020, 31, 22. [CrossRef] 
165. Omurtag, P.S.; Alkan, B.; Durmaz, H.; Hizal, G.; Tunca, U. Indirect functionalization of multiwalled carbon nano tubes through non-covalent interaction of functional polyesters. Polymer 2018, 141, 213-220. [CrossRef]

166. Thankamony, R.L.; Li, X.; Das, S.K.; Ostwal, M.M.; Lai, Z. Porous covalent triazine piperazine polymer (CTPP)/PEBAX mixed matrix membranes for $\mathrm{CO}_{2} / \mathrm{N}_{2}$ and $\mathrm{CO}_{2} / \mathrm{CH}_{4}$ separations. J. Memb. Sci. 2019, 591, 117348. [CrossRef]

167. Zhao, J.; He, G.; Liu, G.; Pan, F.; Wu, H.; Jin, W.; Jiang, Z. Manipulation of interactions at membrane interfaces for energy and environmental applications. Prog. Polym. Sci. 2018, 80, 125-152. [CrossRef]

168. Punetha, V.D.; Rana, S.; Yoo, H.J.; Chaurasia, A.; McLeskey, J.T.; Ramasamy, M.S.; Sahoo, N.G.; Cho, J.W. Functionalization of carbon nanomaterials for advanced polymer nanocomposites: A comparison study between CNT and graphene. Prog. Polym. Sci. 2017, 67, 1-47. [CrossRef]

169. Gerstel, P.; Klumpp, S.; Hennrich, F.; Poschlad, A.; Meded, V.; Blasco, E.; Wenzel, W.; Kappes, M.M.; Barner-Kowollik, C. Highly selective dispersion of single-walled carbon nanotubes via polymer wrapping: A combinatorial study via modular conjugation. ACS Macro Lett. 2014, 3, 10-15. [CrossRef]

170. Basheer, B.V.; George, J.J.; Siengchin, S.; Parameswaranpillai, J. Polymer grafted carbon nanotubes—Synthesis, properties, and applications: A review. Nano-Struct. Nano-Objects 2020, 22, 100429. [CrossRef]

171. Barsbay, M.; Güven, O. Nanostructuring of polymers by controlling of ionizing radiation-induced free radical polymerization, copolymerization, grafting and crosslinking by RAFT mechanism. Radiat. Phys. Chem. 2020, 169, 107816. [CrossRef]

172. Chittrakarn, T.; Tirawanichakul, Y.; Sirijarukul, S.; Yuenyao, C. Plasma induced graft polymerization of hydrophilic monomers on polysulfone gas separation membrane surfaces. Surf. Coat. Technol. 2016, 296, 157-163. [CrossRef]

173. El Yakhlifi, S.; Ball, V. Polydopamine as a stable and functional nanomaterial. Colloids Surf. B Biointerfaces 2020, 186, 110719. [CrossRef] [PubMed]

174. Wang, Z.; Wang, D.; Zhang, S.; Hu, L.; Jin, J. Interfacial Design of Mixed Matrix Membranes for Improved Gas Separation Performance. Adv. Mater. 2016, 28, 3399-3405. [CrossRef]

175. Xu, R.; Wang, Z.; Wang, M.; Qiao, Z.; Wang, J. High nanoparticles loadings mixed matrix membranes via chemical bridging-crosslinking for $\mathrm{CO}_{2}$ separation. J. Memb. Sci. 2019, 573, 455-464. [CrossRef]

176. Casado-Coterillo, C.; del Mar López-Guerrero, M.; Irabien, Á. Synthesis and characterisation of ETS-10/acetate-based ionic liquid/chitosan mixed matrix membranes for $\mathrm{CO}_{2} / \mathrm{N}_{2}$ permeation. Membranes 2014, 4, 287-301. [CrossRef] [PubMed]

177. Ahmad, N.N.R.; Tan, N.I.F.Z.; Leo, C.P.; Ahmad, A.L. Polysulfone-POSS membrane impregnated with ionic liquid for $\mathrm{CO}_{2}$ gas separation. In Proceedings of the 6th International Conference on Environment (ICENV2018): Empowering Environment and Sustainable Engineering Nexus Through Green Technology, Penang, Malaysia, 11-13 December 2018; Volume 2124, p. 030006.

178. Kamble, A.R.; Patel, C.M.; Murthy, Z.V.P. Polyethersulfone based MMMs with 2D materials and ionic liquid for $\mathrm{CO}_{2}, \mathrm{~N}_{2}$ and $\mathrm{CH}_{4}$ separation. J. Environ. Manag. 2020, 262, 110256. [CrossRef]

179. Xie, H.; Zhang, S.; Li, S. Chitin and chitosan dissolved in ionic liquids as reversible sorbents of $\mathrm{CO}_{2}$. Green Chem. 2006, 8, 630-633. [CrossRef]

180. Ng, W.H.; Ahmad, N.N.R.; Leo, C.P.; Ahmad, A.L. Polysulfone/SAPO-34 zeolite membrane impregnated with 1-ethyl-3-methyl imidazolium bis(tri-fluoromethylsulfonyl)imide ionic liquid for $\mathrm{CO}_{2}$ removal. AIP Conf. Proc. 2019, 2124, 030004.

181. Seon Bang, H.; Jang, S.; Soo Kang, Y.; Won, J. Dual facilitated transport of $\mathrm{CO}_{2}$ using electrospun composite membranes containing Ionic liquid. J. Memb. Sci. 2015, 479, 77-84. [CrossRef]

182. Zhang, X.M.; Tu, Z.H.; Li, H.; Li, L.; Wu, Y.T.; Hu, X.B. Supported protic-ionic-liquid membranes with facilitated transport mechanism for the selective separation of $\mathrm{CO}_{2}$. J. Memb. Sci. 2017, 527, 60-67. [CrossRef]

183. Mohshim, D.F.; Mukhtar, H.; Dutta, B.K.; Man, Z. Predicting $\mathrm{CO}_{2}$ Permeation through an Enhanced Ionic Liquid Mixed Matrix Membrane (IL3M). Int. J. Chem. Eng. 2019, 2019, 10. [CrossRef]

184. Hudiono, Y.C.; Carlisle, T.K.; LaFrate, A.L.; Gin, D.L.; Noble, R.D. Novel mixed matrix membranes based on polymerizable room-temperature ionic liquids and SAPO-34 particles to improve $\mathrm{CO}_{2}$ separation. J. Memb. Sci. 2011, 370, 141-148. [CrossRef]

185. Aki, S.N.V.; Mellein, B.R.; Saurer, E.M.; Brennecke, J.F. High-Pressure Phase Behavior of Carbon Dioxide with Imidazolium-Based Ionic Liquids. J. Phys. Chem. B 2004, 108, 20355-20365. [CrossRef] 
186. Li, H.; Tuo, L.; Yang, K.; Jeong, H.K.; Dai, Y.; He, G.; Zhao, W. Simultaneous enhancement of mechanical properties and $\mathrm{CO}_{2}$ selectivity of ZIF-8 mixed matrix membranes: Interfacial toughening effect of ionic liquid. J. Memb. Sci. 2016, 511, 130-142. [CrossRef]

187. Ban, Y.; Li, Z.; Li, Y.; Peng, Y.; Jin, H.; Jiao, W.; Guo, A.; Wang, P.; Yang, Q.; Zhong, C.; et al. Confinement of Ionic Liquids in Nanocages: Tailoring the Molecular Sieving Properties of ZIF-8 for Membrane-Based $\mathrm{CO}_{2}$ Capture. Angew. Chem. Int. Ed. 2015, 54, 15483-15487. [CrossRef] [PubMed]

188. Rhyu, S.Y.; Cho, Y.; Kang, S.W. Nanocomposite membranes consisting of poly(ethylene oxide)/ionic liquid/ZnO for $\mathrm{CO}_{2}$ separation. J. Ind. Eng. Chem. 2020, 85, 75-80. [CrossRef]

189. Ding, S.; Li, X.; Ding, S.; Zhang, W.; Guo, R.; Zhang, J. Ionic liquid-decorated nanocages for cooperative $\mathrm{CO}_{2}$ transport in mixed matrix membranes. Sep. Purif. Technol. 2020, 239, 116539. [CrossRef]

190. Yasmeen, I.; Ilyas, A.; Shamair, Z.; Gilani, M.A.; Rafiq, S.; Bilad, M.R.; Khan, A.L. Synergistic effects of highly selective ionic liquid confined in nanocages: Exploiting the three component mixed matrix membranes for $\mathrm{CO}_{2}$ capture. Chem. Eng. Res. Des. 2020, 155, 123-132. [CrossRef]

191. Wang, D.; Yao, D.; Wang, Y.; Wang, F.; Xin, Y.; Song, S.; Zhang, Z.; Su, F.; Zheng, Y. Carbon nanotubes and graphene oxide-based solvent-free hybrid nanofluids functionalized mixed-matrix membranes for efficient $\mathrm{CO}_{2} / \mathrm{N}_{2}$ separation. Sep. Purif. Technol. 2019, 221, 421-432. [CrossRef]

192. Lin, K.-Y.A.; Park, A.-H.A. Effects of Bonding Types and Functional Groups on $\mathrm{CO}_{2}$ Capture using Novel Multiphase Systems of Liquid-like Nanoparticle Organic Hybrid Materials. Environ. Sci. Technol. 2011, 45, 6633-6639. [CrossRef]

193. Fernandes, N.J.; Wallin, T.J.; Vaia, R.A.; Koerner, H.; Giannelis, E.P. Nanoscale Ionic Materials. Chem. Mater. 2014, 26, 84-96. [CrossRef]

194. Li, P.; Yang, R.; Zheng, Y.; Qu, P.; Chen, L. Effect of polyether amine canopy structure on carbon dioxide uptake of solvent-free nanofluids based on multiwalled carbon nanotubes. Carbon 2015, 95, 408-418. [CrossRef]

195. Ebadi, A.; Omidkhah, M.; Sanaeepur, H.; Kargari, A. Preparation and characterization of Ag ${ }^{+}$ion-exchanged zeolite-Matrimid ${ }^{\circledR} 5218$ mixed matrix membrane for $\mathrm{CO}_{2} / \mathrm{CH}_{4}$ separation. J. Energy Chem. 2016, 25, 450-462. [CrossRef]

196. Peng, D.; Wang, S.; Tian, Z.; Wu, X.; Wu, Y.; Wu, H.; Xin, Q.; Chen, J.; Cao, X.; Jiang, Z. Facilitated transport membranes by incorporating graphene nanosheets with high zinc ion loading for enhanced $\mathrm{CO}_{2}$ separation. J. Memb. Sci. 2017, 522, 351-362. [CrossRef]

197. Vandenabeele, C.R.; Lucas, S. Technological challenges and progress in nanomaterials plasma surface modification-A review. Mater. Sci. Eng. R Rep. 2020, 139, 100521. [CrossRef]

198. Arslan, M.; Tasdelen, M.A. Polymer nanocomposites via click chemistry reactions. Polymer 2017, 9, 499. [CrossRef]

199. Amirkhani, F.; Harami, H.R.; Asghari, M. $\mathrm{CO}_{2} / \mathrm{CH}_{4}$ mixed gas separation using poly(ether-b-amide)- $\mathrm{ZnO}$ nanocomposite membranes: Experimental and molecular dynamics study. Polym. Test. 2020, 86, 106464. [CrossRef]

200. Wang, H.; He, S.; Qin, X.; Li, C.; Li, T. Interfacial Engineering in Metal-Organic Framework-Based Mixed Matrix Membranes Using Covalently Grafted Polyimide Brushes. J. Am. Chem. Soc. 2018, 140, 17203-17210. [CrossRef]

(C) 2020 by the authors. Licensee MDPI, Basel, Switzerland. This article is an open access article distributed under the terms and conditions of the Creative Commons Attribution (CC BY) license (http://creativecommons.org/licenses/by/4.0/). 